\title{
Grafted Neural Progenitors Integrate and Restore Synaptic Connectivity across the Injured Spinal Cord
}

\author{
Joseph F. Bonner, ${ }^{1}$ Theresa M. Connors, ${ }^{1}$ William F. Silverman, ${ }^{1,2}$ David P. Kowalski, ${ }^{1,3}$ Michel A. Lemay, ${ }^{1}$ \\ and Itzhak Fischer ${ }^{1}$ \\ ${ }^{1}$ Department of Neurobiology and Anatomy, Drexel University College of Medicine, Philadelphia, Pennsylvania 19129, ${ }^{2}$ Department of Morphology, \\ Zlotowski Center for Neuroscience, Ben-Gurion University, Beer Sheva 84105, and Israel, ${ }^{3}$ School of Biomedical Engineering, Drexel University, \\ Philadelphia, Pennsylvania 19104
}

\begin{abstract}
Transplantation of neural progenitor cells (NPC) is a promising therapeutic strategy for replacing neurons lost after spinal cord injury, but significant challenges remain regarding neuronal integration and functional connectivity. Here we tested the ability of graft-derived neurons to reestablish connectivity by forming neuronal relays between injured dorsal column (DC) sensory axons and the denervated dorsal column nuclei (DCN). A mixed population of neuronal and glial restricted precursors (NRP/GRP) derived from the embryonic spinal cord of alkaline phosphatase (AP) transgenic rats were grafted acutely into a DC lesion at C1. One week later, BDNF-expressing lentivirus was injected into the DCN to guide graft axons to the intended target. Six weeks later, we observed anterogradely traced sensory axons regenerating into the graft and robust growth of graft-derived AP-positive axons along the neurotrophin gradient into the DCN. Immunoelectron microscopy revealed excitatory synaptic connections between regenerating host axons and graft-derived neurons at $\mathrm{C} 1$ as well as between graft axons and DCN neurons in the brainstem. Functional analysis by stimulus-evoked c-Fos expression and electrophysiological recording showed that host axons formed active synapses with graft neurons at the injury site with the signal propagating by graft axons to the DCN. We observed reproducible electrophysiological activity at the DCN with a temporal delay predicted by our relay model. These findings provide the first evidence for the ability of NPC to form a neuronal relay by extending active axons across the injured spinal cord to the intended target establishing a critical step for neural repair with stem cells.
\end{abstract}

\section{Introduction}

Spinal cord injury (SCI) is characterized by cell death and loss of connectivity with permanent functional deficits. Repair strategies are designed to restore neuronal connectivity by promoting regeneration and plasticity or through cell replacement (Eftekharpour et al., 2008; Verma et al., 2008). Regeneration of axons in the spinal cord, however, is limited by the intrinsic properties of adult CNS neurons and by a postinjury environment inhibitory to axon growth (Cafferty et al., 2008). Consequently, functional regeneration remains challenging despite progress in the characterization of inhibitory molecules and the molecular mechanisms of regeneration (Selzer, 2003). In contrast to regeneration, there is remarkable endogenous plasticity associated with incomplete SCI. Descending corticospinal neurons can form novel circuits with intact propriospinal neurons (Bareyre et al., 2004), and the propriospinal neurons, in turn, serve as a neuronal relay to restore functional connectivity between injured upper motor neu-

Received Aug. 6, 2010; revised Jan. 4, 2011; accepted Feb. 2, 2011.

This work was funded by National Institutes of Health Grant NS055976, Craig H. Neilsen Foundation, Shriners Hospital for Children, and the Drexel University College of Medicine Spinal Cord Research Center. We acknowledge C. Tyler-Polsz, M.-P. Côté, and S. Koutzaki for their assistance with experiments and A. C. Lepore, B. Neuhuber, and M.S. Rao for their helpful discussions. We thank A. Blesch for his generous gift of BDNF lentivirus and A. C. Lepore for the GLT-1 antibody.

Correspondence should be addressed to Dr. Itzhak Fischer, Department of Neurobiology and Anatomy, Drexel University College of Medicine, 2900 Queen Lane, Philadelphia, PA 19129. E-mail: IFischer@drexelmed.edu.

DOI:10.1523/JNEUROSCI.4130-10.2011

Copyright $\odot 2011$ the authors $\quad 0270-6474 / 11 / 314675-12 \$ 15.00 / 0$ rons and intact lower motor neurons (Courtine et al., 2008). A variety of strategies to enhance axon growth have been developed, including digestion of the glial scar (Massey et al., 2006), peripheral nerve grafts (Tom and Houlé, 2008), neurotrophin administration (Cao et al., 2005; Chen et al., 2008; Sasaki et al., 2009), as well as combination treatments. For example, combined cell transplant, neurotrophin gradient, and conditioning lesion elicits axonal bridging of injured dorsal column sensory axons but fails to restore synaptic activity across the lesion (Alto et al., 2009). These studies demonstrate the need to modulate both extrinsic environment and intrinsic capacity of injured neurons to regenerate but underscore the difficulties of regaining functional connectivity even when synaptic structure is restored.

We propose an alternative approach to SCI repair that uses a mix of neuronal and glial restricted progenitors (NRP and GRP, respectively) derived from the embryonic spinal cord as a source of developmentally competent neurons (Fischer et al., 2006) to create a novel neuronal relay. We have shown previously that NRP/GRP grafts generate neurons in the injured spinal cord (Lepore and Fischer, 2005), and these neurons have the intrinsic capacity to overcome chondroitin sulfate proteoglycans (See et al., 2010). Additionally, we have demonstrated that a gradient of brain-derived neurotrophic factor (BDNF) induces guided axon extension from NRP/GRP grafts in the injured spinal cord (Bonner et al., 2010), similar to the role of BDNF in neuronal polarization (Mai et al., 2009), axon guidance (Yao et al., 2006), and synaptogenesis (Causing et al., 1997) during development. In the 
current report, NRP/GRP expressing the human placental alkaline phosphatase (AP) transgenic marker were transplanted into a C1 dorsal columns injury, and NRP axons were guided to the dorsal column nucleus (DCN) with a BDNF gradient. We used immunocytochemistry at light and electron microscope (EM) levels to demonstrate that NRP-derived neurons are capable of establishing afferent and efferent synaptic connections with the injured host at the site of injury and the DCN and used c-Fos expression and electrophysiological analysis to test synaptic activity. Our results demonstrate the ability of NPC to form a neuronal relay across the injured spinal cord and provide the framework for restoring connectivity.

\section{Materials and Methods}

Animal subjects and experimental design Adult (250-300 g) female Sprague Dawley rats $(n=31)$ received a dorsal column lesion at $\mathrm{C} 1$

(Fig. 1) and an acute transplant of $\sim 5 \times 10^{5} \mathrm{NRP} / \mathrm{GRP}$ suspended in 2.5 $\mu$ l of the collagen matrix Purecol (Advanced BioMatrix). NRP/GRP were harvested from animals carrying the human placental AP transgene as verified by PCR. All animals were given daily subcutaneous injections of cyclosporin A (10 mg/kg; Novartis) beginning $3 \mathrm{~d}$ before transplant and/or injury and continuing for the entire study. BDNF-green fluorescent protein (GFP) or GFP lentiviral vector was injected into the dorsal column nuclei $7 \mathrm{~d}$ after injury and cell transplantation. Animals were divided into groups based on vector type and planned analysis as follows: GFP lentivirus for light microscopy $(n=3)$, BDNF-GFP lentivirus for light microscopy $(n=9)$, BDNF-GFP lentivirus for electron microscopy $(n=6)$, control animals with no vector for c-Fos expression $(n=3)$, BDNF-GFP lentivirus for c-Fos expression $(n=2)$, and BDNF-GFP lentivirus for electrophysiology $(n=3)$. Control animals with no vector or transplant for electrophysiology (intact, $n=4$; injured control, $n=1$ ).

\section{Harvest and culture of NRP/GRP}

NRP/GRP were harvested from embryonic day 13.5 spinal cord of Fischer 344 rats expressing the AP transgene. Timed-pregnant females were killed at embryonic day 13.5, and the embryos were placed in DMEM/F-12 (Invitrogen). Meninges were removed from the spinal cords after incubation in collagenase I $(10 \mathrm{mg} / \mathrm{ml}) /$ Dispase II $(20 \mathrm{ng} / \mathrm{ml})$ in HBSS for $9 \mathrm{~min}$ at room temperature. Cords then were treated with trypsin $(0.5 \%) /$ EDTA for $20 \mathrm{~min}$ at $37^{\circ} \mathrm{C}$. Cells were plated on poly-Llysine and laminin in NRP complete medium [DMEM/F-12, BSA (1 $\mathrm{mg} / \mathrm{ml}), \mathrm{B} 27$, basic fibroblast growth factor $(10 \mu \mathrm{g} / \mathrm{ml})$, penicillin-streptomycin $(100 \mathrm{IU} / \mathrm{ml}), \mathrm{N} 2(10 \mu \mathrm{l} / \mathrm{ml})$, and neurotrophin-3 $(10 \mu \mathrm{g} / \mathrm{ml})]$. Medium was changed every $2 \mathrm{~d}$.

\section{Preparation of NRP/GRP for transplantation}

$\mathrm{NRP} / \mathrm{GRP}$ were cultured for 5-6 d before grafting. On the morning of transplantation, cells were dissociated from the culture dish with $0.05 \%$ trypsin-EDTA, and viability was assessed using trypan blue. Cells were suspended at $200,000 \mathrm{cells} / \mu \mathrm{l}$ in a bovine collagen-based grafting medium containing 50\% Purecol and 50\% NRP Basal Medium, pH 7.5. Cells were $\geq 90 \%$ viable based on trypan blue staining and were used within $5 \mathrm{~h}$ of suspension in grafting medium.

\section{Surgical procedures}

Sprague Dawley rats were anesthetized by intraperitoneal injection of a XAK mixture of xylazine (10 mg/kg; J. A. Webster), acepromazine maleate $(0.7 \mathrm{mg} / \mathrm{kg}$; J. A. Webster), and ketamine ( $95 \mathrm{mg} / \mathrm{kg}$; J. A. Webster). Bupranorphin (J. A. Webster) was used for pain relief every $12 \mathrm{~h}$ for $3 \mathrm{~d}$ and then as needed for the remainder of the study. All animals were cared for in accordance with the guidelines established by National Institutes of
Health and the Drexel University College of Medicine Institutional Animal Care and Use Committee.

Dorsal column injury and cell transplantation. A laminectomy was performed at $\mathrm{C} 1$ to expose the spinal cord. The dura was cut along the rostrocaudal axis above the dorsal column. A 30 gauge needle was used to make a complete injury in the right dorsal columns, severing the tract, and a small piece of the dorsal columns was excised using light suction. Although the entire right dorsal column was severed, the left dorsal column was only partially damaged. Sutures (9-0) were placed in the dura on both sides of the lesion but not tightened. After achieving hemostasis of the spinal cord lesion, $\sim 2-3 \mu$ l of cell suspension was injected directly into the cavity, and the dura sutures were quickly tightened to maintain the cell suspension within the lesion site. The muscle was then sutured and the skin stapled.

Vector injection. One week after injury and cell grafting, the animals were injected with BDNF-GFP or GFP vector. Animals were placed in a stereotaxic device with the heads tilted down $45^{\circ}$. A small craniotomy exposed the right DCN, and a 30 gauge needle was used to open the dura. A $10 \mu \mathrm{l}$ Hamilton syringe was fitted with a glass pipette with an external diameter between 70 and $100 \mu$ and used to inject $1.25 \mu$ lof vector at 2 depths ( 1.0 and $0.5 \mathrm{~mm}$ ) in the intact parenchyma of the dorsal column nuclei. The incision was closed and the animals cared for as stated previously. The pLV vector was modified to express GFP or huBDNF-IRES-GFP (Blesch, 2004; Kwon et al., 2007). Vector preparations contained $114 \mu \mathrm{g} / \mathrm{ml} \mathrm{p} 24,8 \times 10 \mathrm{e} 8 \mathrm{TU} / \mathrm{ml}$ for BDNF and $150 \mu \mathrm{g} / \mathrm{ml} \mathrm{p} 24,9 \times 10 \mathrm{e} 8 \mathrm{TU} / \mathrm{ml}$ for GFP.

Cholera toxin subunit $\beta$ labeling. Dorsal column axons were anterogradely labeled with cholera toxin subunit $\beta$ (CT $\beta$ ) (List Biological Laboratories) $3 \mathrm{~d}$ before the animals were killed. An incision was made parallel to the femur to expose the sciatic nerve, and $2 \mu \mathrm{l}$ of CT $\beta$ ( $1 \%$ in distilled water) was injected into the intact sciatic nerve using a $10 \mu \mathrm{l}$ Hamilton syringe fitted with a 30 gauge needle. The incision was closed and the procedure was repeated on the contralateral sciatic nerve. Animals were treated after surgery as stated previously.

Fluoro-Gold labeling. Fluoro-Gold (Fluorochrome) was injected bilaterally into the ventroposterolateral (VPL) thalamus to label DCN neurons in a subset of animals $(n=3)$. Animals were placed in a stereotaxic apparatus, and $0.5 \mu \mathrm{l}$ of the Fluoro-Gold solution ( $2 \%$ in distilled water) was injected at three sites per hemisphere. Coordinates were as follows: $-0.23 \mathrm{~mm}$ rostrocaudal, $\pm 0.30 \mathrm{~mm}$ mediolateral, and $0.55 \mathrm{~mm}$ dorsoventral; $-0.30 \mathrm{~mm}$ rostrocaudal, $\pm 0.32 \mathrm{~mm}$ mediolateral, and $0.55 \mathrm{~mm}$ dorsoventral; and $-0.36 \mathrm{~mm}$ rostrocaudal, $\pm 0.34 \mathrm{~mm}$ mediolateral, and $0.55 \mathrm{~mm}$ dorsoventral.

Immediate early gene $c$-Fos expression. The ipsilateral sciatic nerve was stimulated to induce c-Fos expression in both the graft (monosynaptic) 
and in the DCN (disynaptic). We examined the monosynaptic responses using $0.1 \mathrm{~ms}$ duration, $2 \mathrm{~mA}$ amplitude biphasic pulses applied to the sciatic nerve for $1 \mathrm{~h}$ at a $10 \mathrm{~Hz}$ frequency and examined the disynaptic response using a $100 \mathrm{~Hz}, 300 \mathrm{~ms}$ train of $1 \mathrm{~mA}$ biphasic pulses $(0.1 \mathrm{~ms}$ duration) applied once per second for $1 \mathrm{~h}$. The latter was used to improve summation and increasing firing of graft neurons. Animals were killed $1 \mathrm{~h}$ after termination of the nerve stimulation regimen.

\section{Tissue collection}

Light microscopy. Animals used for histology were killed 6 weeks after injury/cell transplant with an overdose of euthosol (J. A. Webster) and then transcardially perfused with $50-100 \mathrm{ml}$ of ice-cold $0.9 \%$ saline and $500 \mathrm{ml}$ of ice-cold $4 \%$ paraformaldehyde in phosphate buffer. The spinal cord and brainstem were removed and placed in $4 \%$ paraformaldehyde for $24 \mathrm{~h}$, followed by cryoprotection in $30 \%$ sucrose $/ 0.1 \mathrm{~m}$ phosphate buffer at $4^{\circ} \mathrm{C}$ for at least $3 \mathrm{~d}$. Spinal cords were embedded in M1 embedding matrix (Thermo Fisher Scientific) and cut sagitally in $20 \mu \mathrm{m} \mathrm{sec-}$ tions. Tissue was collected on glass slides coated with poly-L-lysine and gelatin. Slides were stored at $4^{\circ} \mathrm{C}$.

Electron microscopy. Animals were killed with an overdose of euthosol (J. A. Webster) and then transcardially perfused with $500 \mathrm{ml}$ of ice-cold $0.2 \%$ glutaraldehyde $/ 4 \%$ paraformaldehyde in phosphate buffer. The spinal cord and brainstem were removed and postfixed in the same solution for $4 \mathrm{~h}$ before being transferred to $0.1 \mathrm{~m}$ phosphate buffer at $4^{\circ} \mathrm{C}$ for storage.

\section{Alkaline phosphatase histochemistry}

Alkaline phosphatase histochemistry was used to visualize transplants and examine process extension. Serial sections (each $\sim 120 \mu \mathrm{m}$ apart) were washed three times in PBS and then placed in $60^{\circ} \mathrm{C}$ PBS for $1 \mathrm{~h}$ to inactivate endogenous phosphatase activity. Sections were then washed in alkaline phosphatase buffer (in mm: 100 Tris, pH 9.5, $50 \mathrm{MgCl}_{2}$, and $100 \mathrm{NaCl}$ ), followed by staining in the dark for $2 \mathrm{~h}$ with AP staining solution $[1.0 \mathrm{mg} / \mathrm{ml}$ nitroblue-tetrazolium-chloride (Sigma), $5 \mathrm{~mm}$ Levamisole (Sigma), and $0.1 \mathrm{mg} / \mathrm{ml}$ 5-bromo-4-chlor-indolyl-phosphate (Sigma) in AP buffer]. All steps were at room temperature unless otherwise noted. Slides were coverslipped with Vectashield (Vector Laboratories). Slides were viewed using Leica DMBRE microscope running Slidebook imaging software ( 3 i Inc.).

\section{Immunohistochemistry}

Slide-mounted tissue sections were treated for $5 \mathrm{~min}$ in $0.2 \%$ Triton $\mathrm{X}-100 / \mathrm{PBS}$, washed three times in PBS for $5 \mathrm{~min}$, and then blocked in $10 \%$ goat serum/PBS for $1 \mathrm{~h}$ at room temperature. Sections were incubated with primary antibodies [mouse $(\mathrm{Ms}) \times$ neuronal-specific nuclear protein $(\mathrm{NeuN}), 1: 100$ (Millipore); rabbit $(\mathrm{Rb}) \times \mathrm{AP}, 1: 200($ Serotec); goat $(\mathrm{Gt}) \times$ cholera toxin, 1:2000 (List Biological Laboratories); guinea pig $(\mathrm{GP}) \times$ Synaptophysin 1 (Synaptic Systems); Rb $\times$ c-Fos, 1:500 (AbCam); Rb $\times$ TrkB 1:500] overnight at room temperature in 2\% serum/ PBS. Sections were then washed three times in PBS to remove unbound primary antibody. Sections were incubated with secondary antibodies $[\mathrm{Gt} \times \mathrm{Rb}$ FITC, Gt $\times$ Ms FITC, Gt $\times$ GP rhodamine, donkey $(\mathrm{Dk}) \times \mathrm{Gt}$ rhodamine, and Dk $\times$ Rb FITC (Jackson ImmunoResearch)] for $2 \mathrm{~h}$, washed three more times in PBS, and coverslipped with Vectashield (Vector Laboratories). Slides were viewed using a Leica DM5500B microscope with Slidebook (3i Inc.) and DP controller (Olympus) or a Carl Zeiss Axioplan microscope with StereoInvestigator software (MicroBrightField).

\section{Preembedded immunoelectron microscopy}

The DCN and C1 spinal cord were sectioned sagitally $(50 \mu \mathrm{m})$ on a vibratome in a bath of ice-cold PBS. To examine the synaptic relationships formed between $\mathrm{AP}$-expressing $\left(\mathrm{AP}^{+}\right)$and host cells, avidin-biotin (ABC; Vector Laboratories) immunohistochemistry was performed using $\mathrm{Rb} \times \mathrm{AP}(1: 100, \mathrm{AbD}$ Serotec) and biotinylated $\times \mathrm{Rb}(1: 200$; Vector Laboratories) IgGs visualized with 3,3'-diaminobenzidine tetrahydrochloride (DAB) (Fast DAB kit; Sigma). The chromagen reaction in some cases was enhanced by addition of nickel ammonium sulfate. In addition to the anti-AP IgG, some sections were colabeled with a mixture of GP $\times$ vesicular glutamate transporter 1 (VGlut1) (1:10,000; Millipore Bioscience Research Reagents) and GP $\times$ vesicular glutamate transporter
2 (VGlut2) (1:2500; Millipore Bioscience Research Reagents). Incubation with the VGlut1 and VGlut2 antisera was followed by exposure to mouse IgG conjugated to $12 \mathrm{~nm}$ gold particles (1:200; Jackson ImmunoResearch). The sections were postfixed in $2 \% \mathrm{OSO}_{4}$ in $0.05 \mathrm{M} \mathrm{PBS}$ for $30 \mathrm{~min}$, rinsed $5 \times$ with the same buffer, and then en bloc stained in $5 \%$ uranyl acetate in $\mathrm{H}_{2} \mathrm{O}$ for $10 \mathrm{~min}$. This was followed by five washes with 5 M sodium maleate buffer and dehydration in 5 min sequential incubations in an ascending ethanol series to propylene oxide. The tissue was embedded in Epon-Araldite between SuperFrost glass slides pretreated with a liquid mold-release agent. Desired regions from the embedded spinal cord segments were mounted onto Epon-Araldite beam capsules, and $80 \mathrm{~nm}$ sections were cut on a Reichart ultramicrotome and collected onto 200 copper mesh grids. The tissue was examined and images digitally recorded on a Jeol 1200EX Transmission Electron Microscope.

\section{Analysis of NRP/GRP grafts: quantitative analyses}

Graft volume, axon extension, $\mathrm{AP}^{+} / \mathrm{NeuN}^{+}$cells, and $\mathrm{AP}^{+} / \mathrm{c}-\mathrm{Fos}^{+}$cells were quantified using StereoInvestigator software, albeit with nonstereological methods. All quantification was performed on every sixth section. Comparisons were made using $t$ tests for volume and $\mathrm{AP}^{+} / \mathrm{NeuN}^{+}$cells, ANOVA with Tukey's post hoc for axon quantification, or $\chi^{2}$ test for average c-Fos ${ }^{+} / \mathrm{NeuN}^{+}$cells. Graft area was quantified using the Cavalieri method of volume estimation with a $100 \times 100 \mu \mathrm{m}$ grid. Coefficient of error for all Cavalieri method analyses (Gunderson $m=1$ ) was $<0.025$. Axons were quantified on the same grid if they intersected the dorsoventral gridline closest to the region of interest [rostral dorsal columns (RDC) or DCN], were at least $100 \mu \mathrm{m}$ in length, and were not associated with a cell soma. The RDC region was defined as the area of the dorsal columns $\sim 0.5 \mathrm{~mm}$ rostral to the lesion site, and the DCN was defined by anatomy and NeuN staining. Axons were counted in the RDC and in the approximate center of the most caudal dorsal column nuclei (gracilis is caudal in the medial brainstem and cuneate is caudal in the lateral). $\mathrm{AP}^{+} / \mathrm{NeuN}^{+}$cells were counted in three animals per treatment group. Figures are presented as averages \pm SEM for all analyses except $\mathrm{AP}^{+} / \mathrm{c}-F o s^{+}$, which is presented as average $\pm \mathrm{SD}$.

\section{Electrophysiological analysis}

Extracellular recordings were made in the ipsilateral gracilis nucleus $(\mathrm{DCN})$ in three groups of animals: intact control (control, $n=4)$, Purcol matrix only (injury, $n=1$ ), and grafted animals with a neurotrophin gradient (gradient, $n=3$ ). A 16-channel electrode (a $4 \times 4$, 3-mm 100-125-177; Neuronexus Technologies) with four sites on each of four shanks, producing a rectangular recording region with a height of 400 $\mu \mathrm{m}$ and width of $500 \mu \mathrm{m}$, was inserted into the DCN with the sites covering the 600-200 $\mu \mathrm{m}$ depth range. Once the electrode was inserted at a given recording site, a train of 100 single stimulus pulse of $1 \mathrm{~mA}$ amplitude (100 $\mu$ s duration, biphasic) at $1 \mathrm{~Hz}$ was applied to the sciatic nerve, and recordings were made on all channels simultaneously using a TDT RZ2 system (Tucker-Davis Technologies). Signals were filtered for multiunit activity (300-4000 Hz, second-order Butterworth bandpass) during recording and then time-reverse filtered in MATLAB (MathWorks) to remove frequency-dependent phase delay. To confirm correct placement of the electrodes, a positive response to stroking or pinching of the ipsilateral hindlimb on some of the channels and null response to stroking or pinching of ipsilateral forelimb pinch and contralateral hindlimb on all of the channels sampled was obtained in all control animals. We also attempted the same procedure in graft and gradient animals; positive response to contact of the ipsilateral hindlimb was not always obtained, but we confirmed that the sites recorded did not respond to pinching or stroking of the other limbs. For each channel, the 100 responses to individual stimulus pulses were aligned to the peak of the stimulus artifacts and averaged to form the peristimulus average response for that channel. Background noise level was calculated as the root mean square (RMS) value of the signal over a 3 ms prestimulus window ( $4 \mathrm{~ms}$ to $1 \mathrm{~ms}$ prestimulus). Furthermore, the peristimulus average was divided into $0.5 \mathrm{~ms}$ windows, and the RMS value of the signal in each window was calculated to obtain the windowed RMS of the response. If the value of that signal after stimulus did not exceed twice the background noise level, that channel was determined to be nonrespon- 


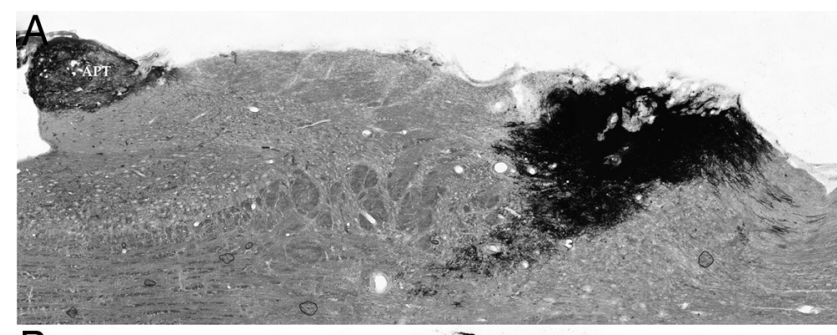

B
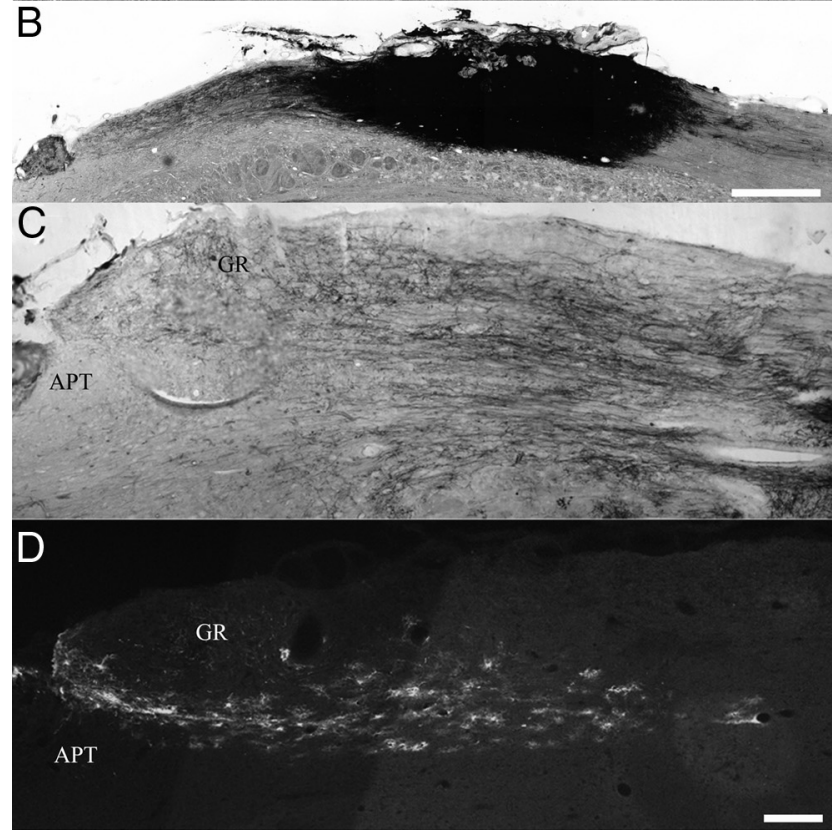

Figure 2. NRP extend axons from an injury at $C 1$ to the $D C N$ along the BDNF gradient. AP NRP/GRP were grafted acutely into a dorsal columns injury, and 1 week later GFP lentivirus ( $\boldsymbol{A}$ ) or BDNF-GFP lentivirus $(\boldsymbol{B})$ was injected into the DCN. NRP/GRP filled the lesion as shown by the dark reaction product of AP histology $(\boldsymbol{A}, \boldsymbol{B})$, but in response to the BDNF gradient $(\boldsymbol{D})$, NRP extended axons from the injury site to the DCN. Examination of consecutive $20 \mu \mathrm{m}$ sections shows that NRP extend axons $(C)$ through areas expressing the GFP reporter of the BDNF-GFP lentivirus (D). GR, Nucleus gracilis; APT, area postrema. Scale bars: $A, B, 500 \mu \mathrm{m} ; \boldsymbol{C}, \mathbf{D}, 100 \mu \mathrm{m}$.

sive and not further analyzed. The latency of the response for each channel was then measured as the time between the onset of stimulus to the point at which the magnitudes of both the peristimulus averaged signal and the windowed RMS of the response exceeded twice the background level. The process was repeated for every channel individually, and the latencies for each set of animals were grouped together. Welch's $t$ test for unpaired data with nonmatching variance was used to assess the statistical significance of the difference in the latency of the DCN responses to stimulation of the sciatic nerve between the groups.

\section{Results}

\section{Graft-derived neurons extend axons to the DCN along a} BDNF gradient

We acutely grafted NRP/GRP derived from AP transgenic rats into a $\mathrm{C} 1$ dorsal columns lesion to test the ability of graft-derived neurons to integrate and extend axons from the injury site to a target in the brainstem. One week after the grafting, we injected GFP lentivirus or BDNF-GFP lentivirus into the DCN (Fig. 1). Six weeks later, AP histology showed that the grafted cells survived and filled the injury site but did not extend long processes in response to control GFP lentivirus (Fig. $2 \mathrm{~A}$ ). In contrast, injection of BDNF-GFP lentivirus into the DCN resulted in robust axon growth by graft neurons from the lesion site into the DCN (Fig. $2 B, C$ ). Graft axons primarily grew rostrally along the white matter tracts, although some axons were also observed extending
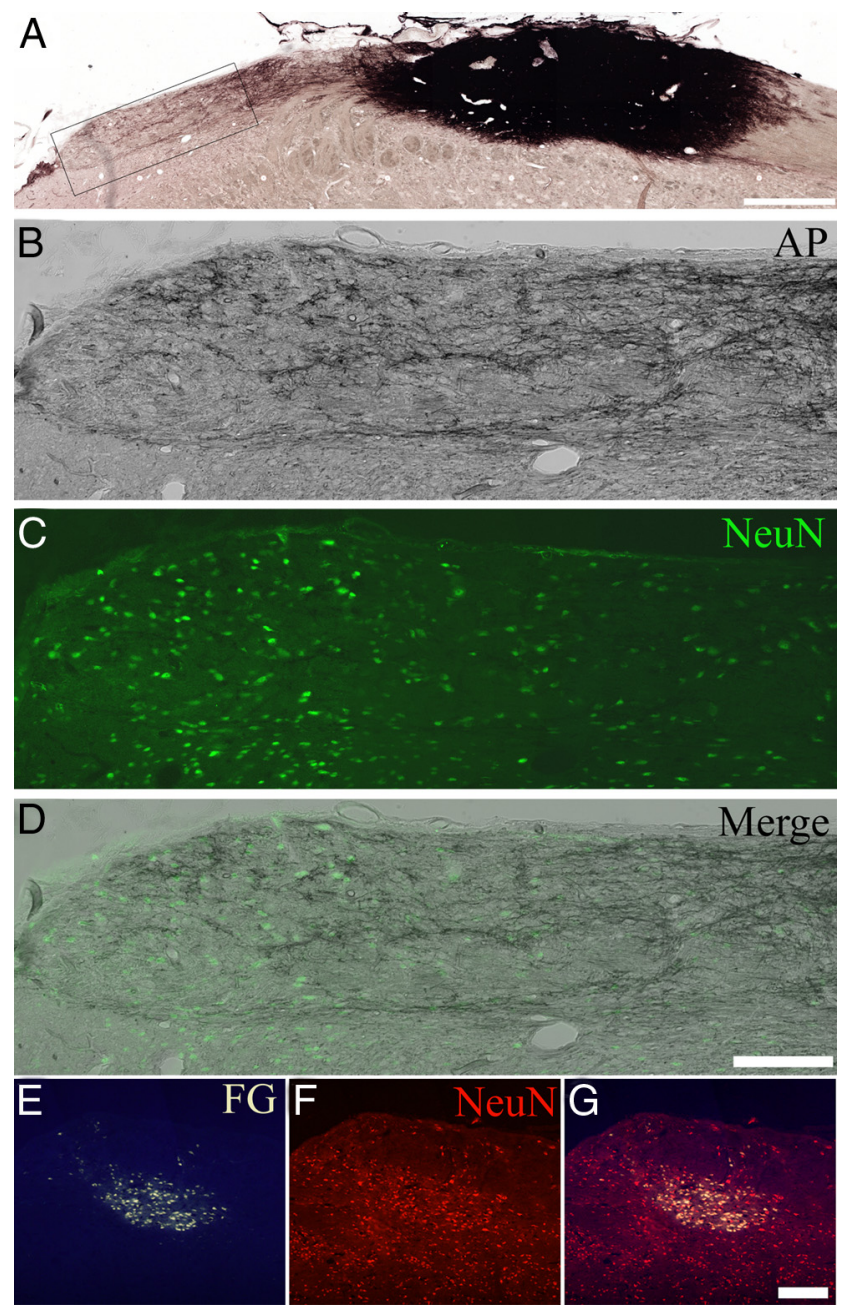

Figure 3. BDNF guides $\mathrm{AP}^{+}$axons into the DCN. AP histology demonstrates that NRP/GRP grafts fill the lesion site and extend axons to the DCN in response to the BDNF gradient $(\boldsymbol{A})$. The boxed region $(A)$ is shown at high magnification with double staining for AP histology $(B, D)$ and immunofluorescence of the neuronal nuclei marker (NeuN). The images of $A P(B)$ and NeuN $(\boldsymbol{C}$ ) have been merged ( $\boldsymbol{D})$ to demonstrate that $\mathrm{AP}^{+}$axons extend into the neuron-dense DCN. A subset of animals received injection of Fluoro-Gold into the VPL thalamus to retrogradely label the DCN. The combination $(G)$ of Fluoro-Gold tracing $(\boldsymbol{E} ; \mathrm{FG})$ and NeuN labeling $(\boldsymbol{F})$ confirms that graft axons reached DCN neurons, which project to the VPL thalamus. Scale bars: $A, 400 \mu \mathrm{m} ; \boldsymbol{B}-\mathbf{G}, 100 \mu \mathrm{m}$.

caudally from the graft (Fig. $2 B$ ). We have reported previously that injection of BDNF-GFP lentivirus into the DCN creates a gradient of BDNF from the DCN to $\mathrm{C} 1$ within 2 weeks of infection as verified by BDNF ELISA and GFP immunohistochemistry (Bonner et al., 2010). In the current report, we observed a similar pattern of GFP expression after injection of BDNF-GFP lentivirus into the DCN (Fig. 2D). Dense $\mathrm{AP}^{+}$axons (Fig. 2C) were observed growing along the dorsal columns and entering the DCN in the same region that showed GFP expression, indicating a close relationship between graft axon growth and host cells infected by the BDNF-GFP lentivirus. Graft axons were primarily oriented longitudinally in the dorsal columns, and only few axons were observed growing into the ventral gray matter.

We quantified the effects of the BDNF gradient on several properties of the NRP/GRP graft. The presence of the gradient was associated with an overall expansion of the area occupied by graft-derived cells from $0.59 \pm 0.1 \mathrm{~mm}^{3}$ in the control group to $1.39 \pm 0.1 \mathrm{~mm}^{3}$ in the BDNF group ( $t$ test, $p<0.05$ ), indicating an increase in cell number and/or migration. We observed an $3 \times$ 


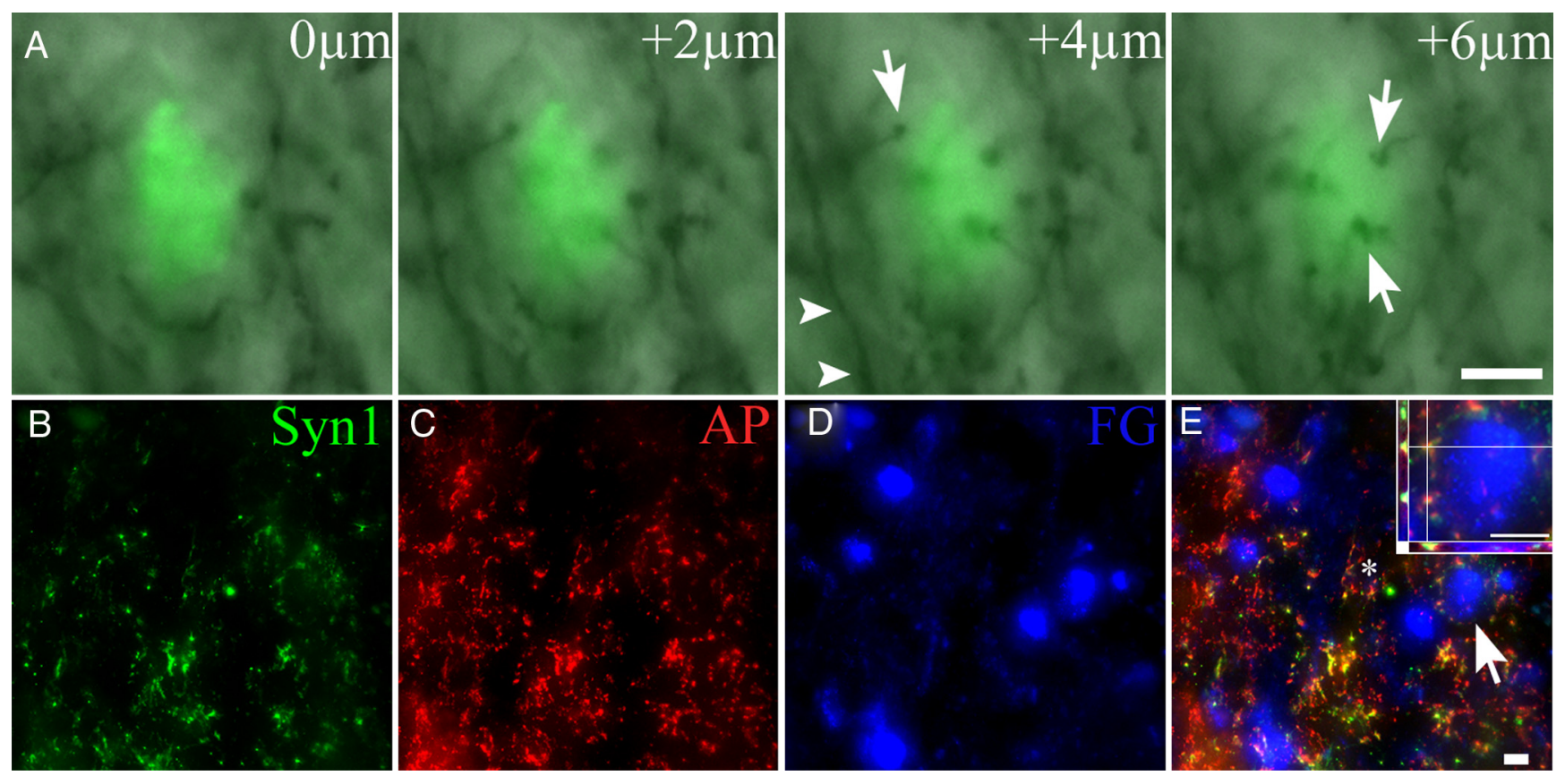

Figure 4. $\quad \mathrm{AP}^{+}$axons reach the $\mathrm{DCN}$ and express presynaptic markers. Images from consecutive $2 \mu \mathrm{m}$ focal planes show $\mathrm{AP}^{+}$synaptic, bouton-like structures $(A$, arrows) encompassing a host neuron $\left(\mathrm{AP}^{-}\right.$) labeled with NeuN (green, $\boldsymbol{A}$ ) as well as an $\mathrm{AP}^{+}$axon passing the host neuron $\left(\boldsymbol{A}\right.$, arrowheads). $\mathrm{AP}^{+}$axons (red, $\left.\boldsymbol{C}, \boldsymbol{E}\right)$ express the presynaptic marker synaptophysin (green, $\boldsymbol{B}, \boldsymbol{E}$; Syn 1 ) in close apposition to hostneurons retrogradely labeled with Fluoro-Gold (blue, $\boldsymbol{D}, \boldsymbol{E} ; \boldsymbol{F} \mathrm{F})$ from the VPL thalamus. The arrow $(\boldsymbol{E})$ indicates a Fluoro-Gold-labeled neuron $\left(\boldsymbol{E}\right.$, inset) that is closely apposed by an $A \mathrm{P}^{+}$process colabeled with several puncta of synaptophysin $(\boldsymbol{E})$. There were similar $\mathrm{AP}^{+} /$Synaptophysin ${ }^{+}$double-labeled structures that did not appose Fluoro-Gold-labeled neurons (asterisk, $\boldsymbol{D}$ ), indicating that Fluoro-Gold only labels a fraction of DCN neurons. Scale bars, $10 \mu \mathrm{m}$.
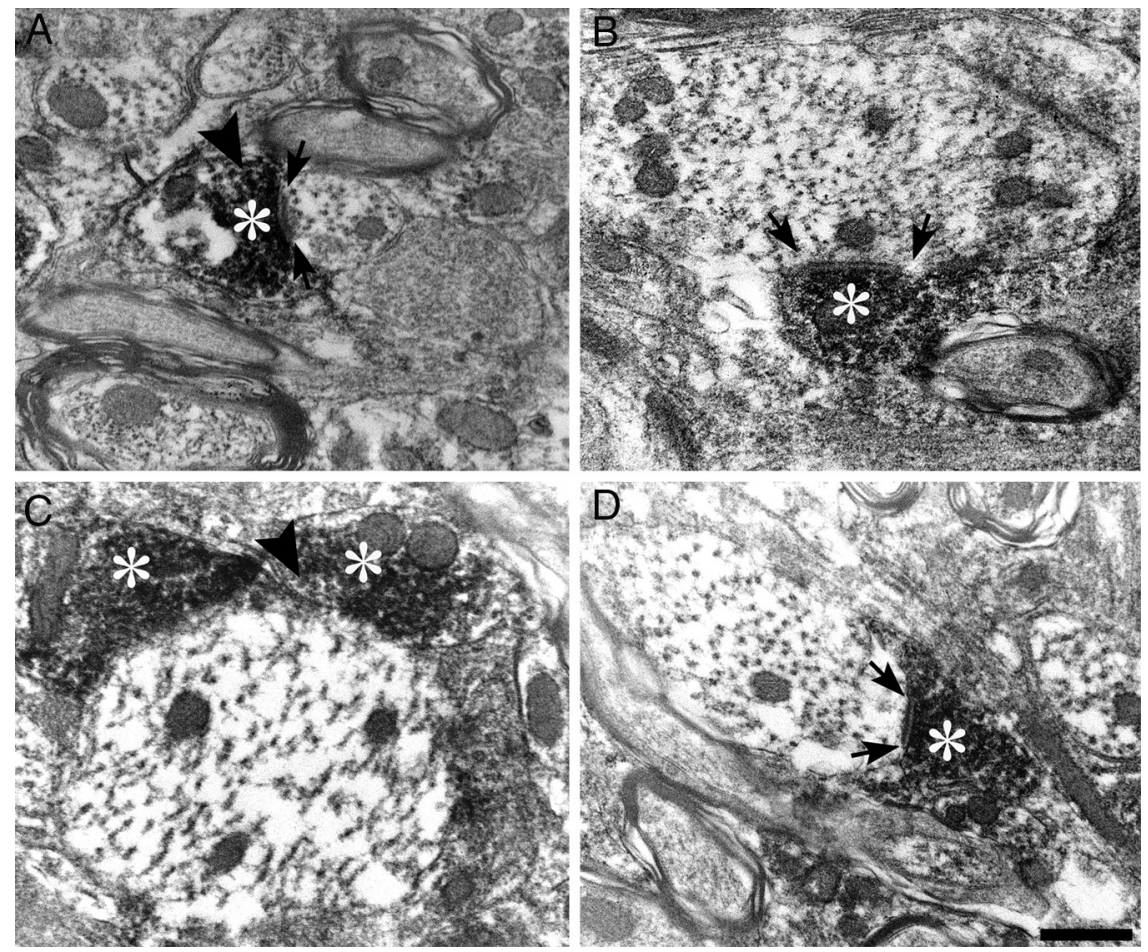

Figure 5. $\mathrm{AP}^{+}$axons form synaptic structures in the DCN. Immuno-EM analysis of the DCN revealed $A P^{+}$presynaptic structures (asterisks, $\boldsymbol{A}-\boldsymbol{D})$ from graft axons apposed to host $\left(\mathrm{AP}^{-}\right)$dendrites. There were instances of both single $A \mathrm{P}^{+}(\boldsymbol{A}, \boldsymbol{B}, \boldsymbol{D})$ and multiple presynaptic terminals contacting one host dendrite ( $($ ). Note that the high density of nickel-enhanced DAB labeling obscures the detail of presynaptic vesicles, but they can be seen clustered near the presynaptic membrane (arrowheads), whereas PSDs are present in most AP host dendrites (arrows, $A, B, D$ ). Scale bar, $500 \mathrm{~nm}$.

increase in average number of $\mathrm{NeuN}^{+} / \mathrm{AP}^{+}$cells per $20 \mu \mathrm{m} \mathrm{sec}-$ tion from $49.95 \pm 8.8$ in the GFP group to $159.93 \pm 27.8$ in the BDNF group ( $t$ test, $p<0.05$ ), suggesting an increase in NRP proliferation and/or neuronal survival. Finally, we quantified the number of axons extending rostrally through the dorsal columns and the number of axons entering the DCN. In the BDNF group, an average of 142.6 axons extended through the dorsal columns and 102.5 , representing $71 \%$, reached the DCN. In contrast, only an average of 8.4 axons were present in the dorsal columns and virtually none reaching the DCN $(<1)$ in the GFP group. Both the number of axons in the dorsal columns and the DCN were greater in the BDNF group versus control, but there was no significant difference between the number of axons in the dorsal columns and those that reached the DCN in the BDNF group (ANOVA, $p<0.05$; Tukey's post hoc, $p<0.05)$.

\section{Graft axons innervate the DCN}

We next combined AP histology and NeuN immunofluorescence on the same sections to assess the relationship between graft axons and host neurons in the DCN. This combination exploited the highresolution and contrast of AP histology relative to immunofluorescence to identify graft-derived axons. $\mathrm{AP}^{+}$axons from graft neurons (Fig. 3A) grew along the dorsal columns (Fig. $3 B$ ) and were distributed throughout areas of dense NeuN staining (Fig. $3 C, D$ ) in the DCN. In a subset of animals, we compared retrograde labeling of DCN neurons, using Fluoro-Gold (Fig. $3 E, G$ ) with the NeuN staining (Fig. $3 F, G$ ), and observed a cluster of double- 
labeled neurons, which confirmed that graft axons had indeed reached the DCN.

We further examined the DCN of animals in the BDNF group for evidence of synaptic connections between graft axons and host neurons. Using high-magnification optical serial $Z$-sections, we observed individual cell bodies of DCN neurons surrounded by numerous $\mathrm{AP}^{+}$synaptic structures in which bouton-like terminals were juxtaposed to host cell bodies (Fig. 4A), suggesting multiple presynaptic connections. Similarly, we observed punctate synaptophysin expression in $\mathrm{AP}^{+}$axons (Fig. $4 B, C, E)$ in apparent contact with retrogradely Fluoro-Gold-labeled neurons (Fig. $4 D, E)$. High magnification revealed an $\mathrm{AP}^{+}$axon with multiple synaptophysin ${ }^{+}$ puncta apposed to a Fluoro-Gold-labeled neuron (Fig. $4 E$, inset), again indicating that graft axons established synaptic connections with host neurons.

Next, we assessed the efferent connectivity and synapse formation of graftderived neurons with targets in the DCN using the classical structural definition of a synapse, which requires clustering of vesicles in the presynaptic element and a postsynaptic density (PSD) (Peters et al., 1970). Immuno-EM analysis revealed frequent synaptic contacts between $\mathrm{AP}^{+}$terminals and host neurons $\left(\mathrm{AP}^{-}\right)$in the $\mathrm{BDNF}$ group. Typically, single $\mathrm{AP}^{+}$synaptic boutons were seen apposed to host dendrites (Fig. 5A,B,D), but examples of multiple $\mathrm{AP}^{+}$boutons contacting a single host dendrite were also observed (Fig. $5 C)$. Prominent PSDs were often seen in the host dendrite (Fig. 5A, B,D, arrows), suggesting these were excitatory axodendritic synapses of the type normally observed in the DCN. However, we occasionally observed $\mathrm{AP}^{+}$synaptic boutons without a clear PSD (Fig. 5C). This may be the result of a PSD that is outside the 80nm-thick EM section or may indicate symmetrical, inhibitory synapses or immature synapses. Aside from the presence of a PSD, dendrites were also identified by the orderly arranged microtubules, paucity of organelles other than mitochondria and lack of neurofilaments (Peters et al., 1970).

\section{Graft axons may also connect with unintended targets}

Although the majority of graft axons were directed to the DCN, we also observed some $\mathrm{AP}^{+}$axons growing into an unintended target, the caudal spinal trigeminal nucleus (SN5). However, we have only documented a single case in which the majority of the axons grew through the SN5 and not the DCN target (Fig. 6A-C). We carefully examined these errant axons to determine whether graft neurons could also, in general, connect
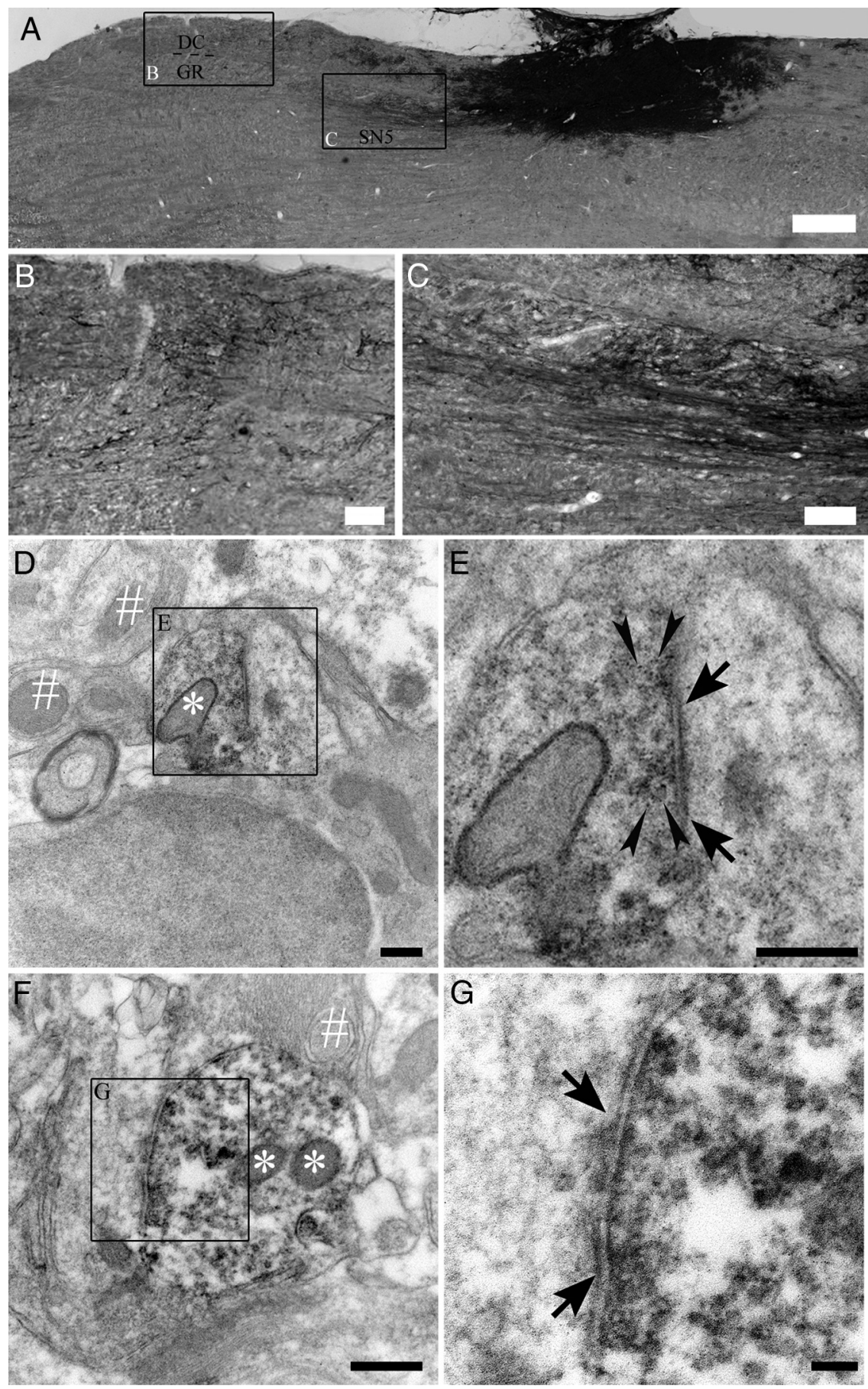

Figure 6. $\mathrm{AP}^{+}$axons may also connect with unintended targets. Although in most cases $\mathrm{AP}^{+}$axons extended only into the $D C N$, this figure shows an example of growth into the SN5 $(A, C$. Despite the growth into the SN5, many axons still grew through the dorsal columns $(A, B, D C)$ and into the nucleus gracilus $(A, B, G R)$. Immuno-EM of the SN5 demonstrated that graft axons made presynaptic connections with host neurons $(\boldsymbol{D}, \boldsymbol{F})$. The boxed regions in $\boldsymbol{D}$ and $\boldsymbol{F}$ are shown at high magnification $(\boldsymbol{E}, \boldsymbol{G})$ to underscore the clustering of synaptic vesicles at the presynaptic membrane and the thick PSDs (arrows, $E, G$ ). Double immuno-EM $(\boldsymbol{D}, \boldsymbol{E})$ was performed by labeling $\mathrm{AP}^{+}$axons with $\mathrm{DAB}$ and vesicular glutamate transporter 1 and 2 with $12 \mathrm{~nm}$ gold particles. DAB labeling of $\mathrm{AP}^{+}$synaptic boutons is most evident in the mitochondrial membranes $\left({ }^{*}, \boldsymbol{D}, \boldsymbol{F}\right)$ compared with unlabeled mitochondria $(\#, \boldsymbol{D}, \boldsymbol{F})$. Synaptic vesicles cluster at the presynaptic membrane $(\boldsymbol{D}-\boldsymbol{F})$, and some vesicles are labeled with the gold particles (arrowheads, E). Scale bars: $\boldsymbol{A}, 500 \mu \mathrm{m} ; \boldsymbol{B}, \boldsymbol{C}, 100 \mu \mathrm{m} ; \boldsymbol{D}-\boldsymbol{F}, 500 \mathrm{~nm} ; \boldsymbol{G}, 100 \mathrm{~nm}$.

with intact nuclei, which are not the designated target. Specifically, we used immuno-EM to evaluate the nature of the connectivity between graft axons and host neurons in the SN5. Using a dual-label approach to identify graft-derived $\mathrm{AP}^{+}$axons with $\mathrm{DAB}$ and glutamatergic synapses expressing VGlut1 and VGlut2 

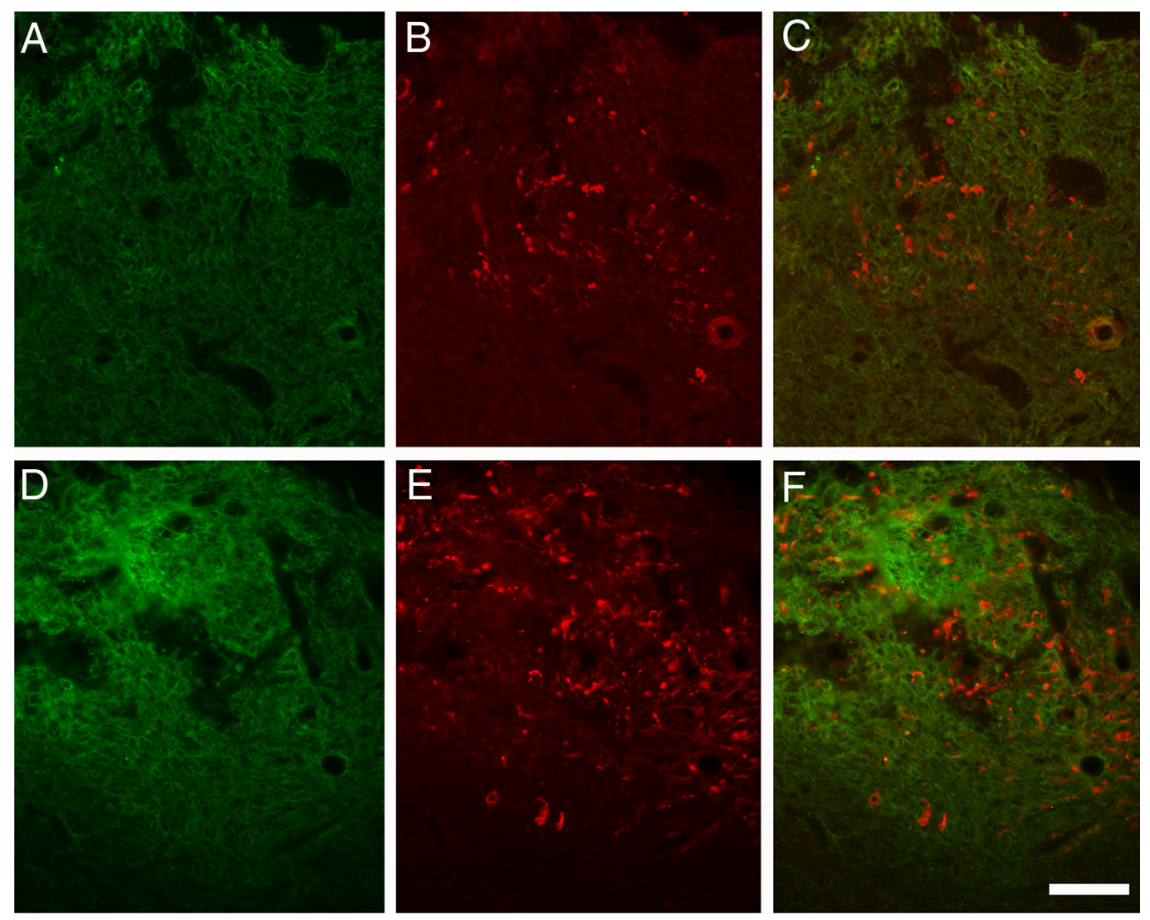

Figure 7. Host axons regenerate into NRP/GRP grafts. Three days before the animals were killed, CT $\beta$ was injected bilaterally into the sciatic nerves to anterogradely label regenerating axons. Traced neurons regenerated $(B, E)$ throughout $\mathrm{AP}^{+}$graft region $(\boldsymbol{A}, \boldsymbol{D})$ in both the GFP group $(\boldsymbol{A}-\boldsymbol{C})$ and BDNF group $(\boldsymbol{A}-\boldsymbol{F})$. However, CT $\beta$-labeled axons were not observed to transverse the grafting site and reenter the intact host parenchyma rostral to the injury. Scale bar, $100 \mu \mathrm{m}$.

with gold particles, we observed axo-dendritic synapses between graft-derived terminals (Fig. 6D, F, asterisks) and host dendrites in the SN5 (Fig. $6 D-G$ ), with synaptic vesicles immunopositive for VGlut1 and VGlut2 (Fig. $6 E$, arrowheads). The presence of the glutamate transporter together with a prominent postsynaptic density (Fig. $6 E, G$, arrows) identifies the synapses as excitatory. These findings indicate that a BDNF gradient will induce and guide axon growth and also demonstrate that a single, attractive gradient may not always be sufficient to guarantee complete specificity in axon guidance. Adding repulsive cues may improve navigation to the designated target as demonstrated previously with transplanted neurons that followed NGF cues along the midline of the corpus callosum, turning in response to the repulsive signaling molecule semaphorin3a (Ziemba et al., 2008).

\section{NRP/GRP support host axon regeneration and formation of synapses with graft neurons}

CT $\beta$ was injected bilaterally into the sciatic nerves $3 \mathrm{~d}$ before the animals were killed to label regenerating sensory afferents. In the GFP (control) group, we found that the NRP/GRP graft (Fig. $7 A, C$ ) supported the regeneration of CT $\beta$-labeled axons (Fig. $7 B$ ) into but not beyond the graft (Fig. $7 C$ ). We observed similar regeneration in the BDNF group (Fig. 7D) with CT $\beta$-labeled axons (Fig. $7 E$ ) present throughout but not rostral to the graft (Fig. $7 F$ ). These results indicate that the NRP/GRP graft alone can support limited regeneration of injured host axons.

Using immuno-EM, we then documented synaptic connections between graft-derived $\mathrm{AP}^{+}$dendrites and host axons at the injury site (Fig. 8). For example, a single $\mathrm{AP}^{+}$dendrite (Fig. $8 \mathrm{~A}$, asterisk) is shown surrounded by four host ( $\mathrm{AP}-$ ) synaptic boutons. Two of these boutons are shown at higher magnification (Fig. $8 C, D$ ) to highlight the synaptic vesicles and PSDs (Fig. 8C,D, arrows). Another $\mathrm{AP}^{+}$dendrite (Fig. $8 \mathrm{~B}$ ) is contacted by an $\mathrm{AP}^{-}$ host axon (Fig. $8 B$, labeled E) and an $\mathrm{AP}^{+}$ graft axon (Fig. $8 B$, labeled F). High magnification of the $\mathrm{AP}^{-}$synaptic bouton (Fig. 8E) shows synaptic vesicles docked at the membrane together with a welldefined PSD (Fig. $8 E$, arrows). The observation of intragraft connectivity in addition to host-graft connectivity indicates the robust ability of graft neurons to form both presynaptic and postsynaptic elements in the injured spinal cord.

\section{NRP/GRP grafts express c-Fos in response to sciatic nerve stimulation}

The rapid and transitory expression of c-Fos has been widely used for the identification of neurons that respond to an acute stimulus (Cohen and Greenberg, 2008), including spinal cord neurons that respond to sensory stimulation (Hunt et al., 1987). We therefore used c-Fos expression to examine connectivity between regenerating dorsal column axons and graft neurons in animals with an NRP/ GRP graft in a C1 lesion without BDNF treatment $(n=3)$. Six weeks after injury and transplantation, the ipsilateral sciatic nerve was stimulated for $1 \mathrm{~h}$ using a hook electrode. Animals were killed $1 \mathrm{~h}$ later and evaluated by immunofluorescence for c-Fos expression. In the unstimulated (control) group, we found only few graft cells that expressed c-Fos (Fig. 9A-C) in their nuclei. In contrast, the stimulated group showed robust expression of c-Fos (Fig. 9D-F) in many more cells, demonstrating a direct effect of sensory axon stimulation on NRP/GRP grafts. Expression of c-Fos in neurons requires repeated firing of action potentials. In turn, glutamatergic synapses require astrocytes to recycle extracellular glutamate to maintain high firing rates. $\mathrm{AP}^{+}$graft cells $(G, I)$ expressed the astrocytic glutamate transporter GLT-1 $(H, I)$, a critical element of glutamatergic synapses. Double staining of NeuN (Fig. 10A,C) and c-Fos (Fig. $10 B, C)$ in the graft site showed that, whereas in the unstimulated group only $9.3 \pm 2.1 \%$ of the $\mathrm{NeuN}^{+}$neurons expressed c-Fos (Fig. $10 D)$, almost half of graft neurons $(48.5 \pm 4.7 \%)$ (Fig. $10 D)$ expressed c-Fos after sciatic nerve stimulation a significant increase over unstimulated grafts $(p<0.01)$, demonstrating connectivity between sensory axons and graft neurons.

We used a similar paradigm to analyze c-Fos expression in DCN neurons in animals that received a combination treatment of acute NRP/GRP graft and delayed BDNF gradient $(n=2)$. We only found few examples of cells that were $\mathrm{NeuN}^{+} / \mathrm{c}-\mathrm{Fos}^{+}$(Fig. $10 \mathrm{E}-\mathrm{G}$ ). These cells were found adjacent to $\mathrm{AP}^{+}$processes (Fig. $10 \mathrm{H}$ ).

\section{NRP/GRP receive and relay sensory information to the DCN}

To functionally test the NRP/GRP relay, extracellular recordings were made in the DCN ipsilateral to the stimulated sciatic nerve. Using a 16-channel electrode, we sampled a total of 64 sites in four intact control animals and 48 sites in three BDNF gradient animals with all the channels being responsive. Completeness of the dorsal column lesion was confirmed histologically for the three BDNF gradient animals (data not shown). A representative peristimulus averaged signal from a BDNF gradient animal (dot- 


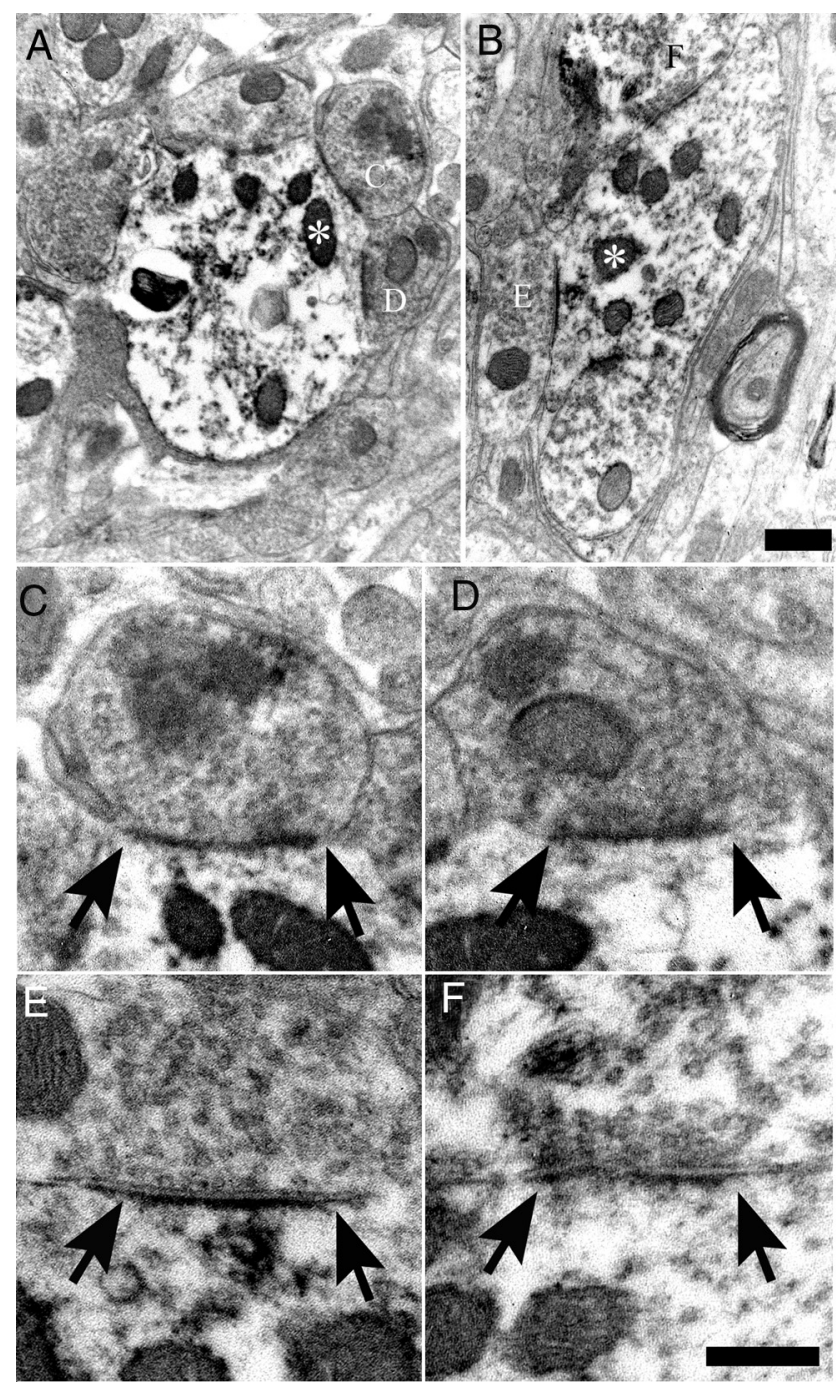

Figure 8. Host axons regenerate and form synaptic connections with graft neurons. Immuno-EM analysis demonstrated connectivity between $\mathrm{AP}^{+}$neurons (AP signal is most evident in the mitochondria, labeled with ${ }^{*}$ ) and regenerating host axons $\left(\mathrm{AP}^{-}\right)$. Four synaptic boutons from host axons $(\boldsymbol{A})$ are shown to made synaptic connections with a graft dendrite $\left({ }^{*}, \boldsymbol{A}\right)$. Two of these boutons are displayed at higher magnification $(\boldsymbol{C}, \boldsymbol{D})$, showing vesicles clustered at the presynaptic membranes and PSDs present at the postsynaptic membrane (arrows, $\boldsymbol{C}, \boldsymbol{D})$. Another example demonstrates that synaptic boutons from both host and graft can connect with a graft dendrite $\left({ }^{*}, \boldsymbol{B}\right)$. The synaptic boutons from host $(\boldsymbol{E})$ and graft $(\boldsymbol{F})$ are displayed at higher magnification again showing vesicles docked at the presynaptic membrane $(\boldsymbol{E}, \boldsymbol{F})$ and thick PSDs (arrows, $\boldsymbol{E}, \boldsymbol{F})$. Scale bars: $\boldsymbol{A}, \boldsymbol{B}, 400 \mathrm{~nm} ; \boldsymbol{C}, \boldsymbol{D}, 200 \mathrm{~nm}$.

ted line) along with the windowed RMS response (heavy weight line) is shown in (Fig. 11A). Response latency was calculated as the time difference between onset of stimulus artifact and the time at which the magnitude of both the signal and signal RMS are greater than twice the background level (Fig. 11A). The windowed RMS value of the responses in the control and BDNF groups were averaged and shown with 95\% confidence intervals (Fig. $11 B$ ). Our data show that the response to stimulation of the sciatic nerve measured in the DCN is reduced and delayed in the BDNF group compared with the intact controls. When the latencies of individual channels were compared, the average latency of the DCN response to sciatic nerve stimulation was $3.98 \pm 0.63 \mathrm{~ms}$ in control animals ( 64 channels responsive over 64 sites sampled) and $5.23 \pm 0.32 \mathrm{~ms}$ in the BDNF group ( 48 channels over 48 sites sampled) (Fig. 11C). When we sampled 32 sites in one injured animal with no NRP/GRP graft, we found that 31 sites showed no response and the one responsive channel displayed latency of an intact fiber (data not shown). The difference in latencies between control and BDNF groups (1.25 ms) was statistically significant $(p<0.01$, Welch's $t$ test). The latency in control animals $(3.98$ $\mathrm{ms}$ ) was similar to published data that reported a latency of $\sim 3.8$ $\mathrm{ms}$ for responses in the dorsal columns just caudal to the nucleus (McComas, 1963) but suggest that our extracellular recordings were from axons entering the DCN because a latency of $\sim 4.8 \mathrm{~ms}$ was reported for responses from single cells postsynaptic response in the gracilis nucleus (McComas, 1963). Together, these data suggest that the latency we measured in control animals is a result of the compound action potential of fibers entering the gracilis nucleus and that $\sim 0.9 \mathrm{~ms}$ of the $1.25 \mathrm{~ms}$ delay in latency that we observed in the BDNF group is the result of the synaptic delay (Wayner and Emmers, 1958) between the sensory axons and graft neurons. The remaining delay can be accounted for by the axonal conduction of the graft axons entering the DCN. In addition, a number of sites in the DCN were responsive to light pinching or stroking of the animal's ipsilateral hindpaw in the gradient animal as shown in Figure $11 E$ but not to stroking or pinching of the contralateral hindlimb or ipsilateral forelimb, supporting the conclusion that dorsal columns axons made functional synapses with graft neurons whose axons projected to the DCN. We tested the presence of a response to stimulation recruiting primarily larger sciatic nerve axons [stimulus intensity below $2 \times$ the motor threshold (MT)] in a number of animals. We used a stimulus of $1.2 \times \mathrm{MT}$ to recruit only the largest myelinated dorsal column sensory axons, a $1 \mathrm{~mA}$ stimulus to recruit all fibers, and $2 \times \mathrm{MT}$ as an intermediate stimulus. We found that the latency of the response to stimuli at $1.2 \times \mathrm{MT}$ was identical to the fastest latency observed for stimulation at $2 \times \mathrm{MT}$ and $1.0 \mathrm{~mA}$ (Fig. 11D). This suggests that the early responses observed in the BDNF group at all intensities are from large myelinated sensory fibers connecting with the graft and not from small-caliber fibers connecting through alternative circuits. We also observed that, with increased stimuli intensity, the response at longer latencies was also increased as additional sensory axons are recruited with increased stimulation (Fig. $11 \mathrm{D}$ ). We made repeated attempts to expose the graft site at $\mathrm{C} 1$ to allow for direct extracellular recording in the graft and to inject glutamatergic antagonists in the graft during DCN recording. However, adhesion between the dura and spinal cord prevented exposure of the graft without damaging the graft. In addition, we found that bath applications of antagonists were impractical because of the proximity of $\mathrm{C} 1$ and the DCN as well as $\mathrm{C} 1$ and the phrenic motor pool.

Action potentials from fibers entering the DCN as well as postsynaptic cells firing contribute to the extracellular recording responses, and thus we cannot assess whether the responses in the DCN are action potentials recorded from the fibers entering the DCN or the firing of the cells in the DCN. The limited number of neurons showing c-Fos expression after stimulation of the sciatic nerve in BDNF gradient animals suggests that action potentials from graft axons entering the DCN are the major contributor to the responses recorded. At a minimum, the results indicate that the dorsal column axons make functional synapses with the grafted cells and that graft axons projecting to the DCN are capable of conducting action potentials.

\section{Discussion}

Neural progenitors can be generated from induced pluripotent stem cells, embryonic stem cells, and fetal tissue (Mujtaba et al., 1999; Cummings et al., 2005), making replacement of glia and 

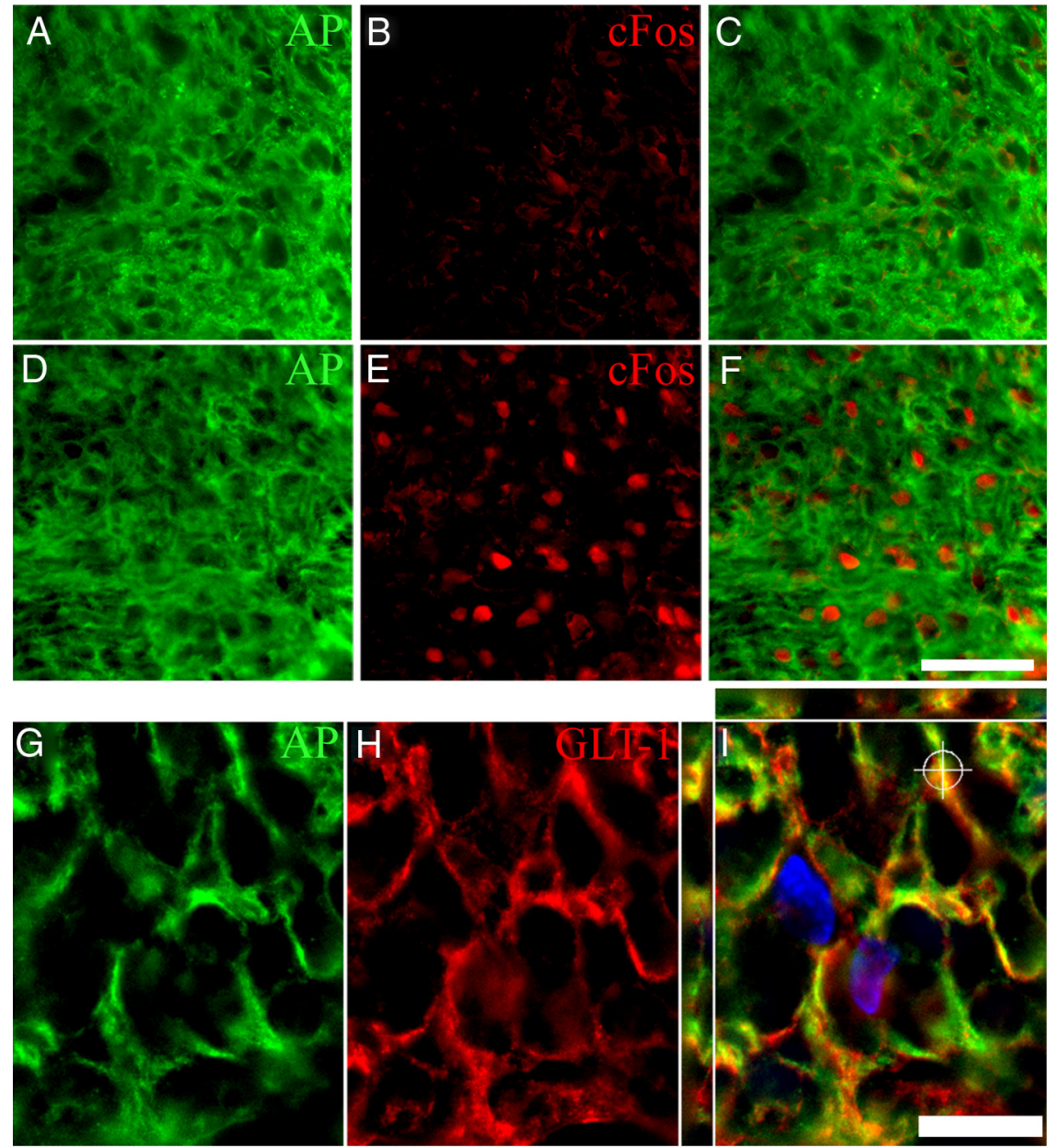

Figure 9. Electrical stimulation of dorsal column axons evokes robustc-Fos expression in graftneurons. The sciaticnerve wasstimulated to determine if graft cells and DCN neurons would express the immediate early gene $c$-Fos, an indicator of synaptic activity in response to stimulation. Control, unstimulated $\mathrm{AP}^{+}$graftcells $(\boldsymbol{A}, \boldsymbol{C})$ showed limited c-Fos expression $(\boldsymbol{B}, \boldsymbol{C})$, whereas stimulated $\mathrm{AP}^{+}$graft cells $(\boldsymbol{D}, \boldsymbol{F})$ showed robust, nuclear c-Fos staining $(\boldsymbol{E}, \boldsymbol{F})$. Additionally, $\mathrm{AP}^{+}$graft cells $(\boldsymbol{G}, \boldsymbol{I})$ expressed the astrocytic glutamate transporter GLT- $1(\boldsymbol{H}$, I), a critical requirement for repetitive glutamatergic synaptic transmission and c-Fos expression. Scale bars: $A-F, 50 \mu \mathrm{m} ; \mathbf{G}-I, 10 \mu \mathrm{m}$.
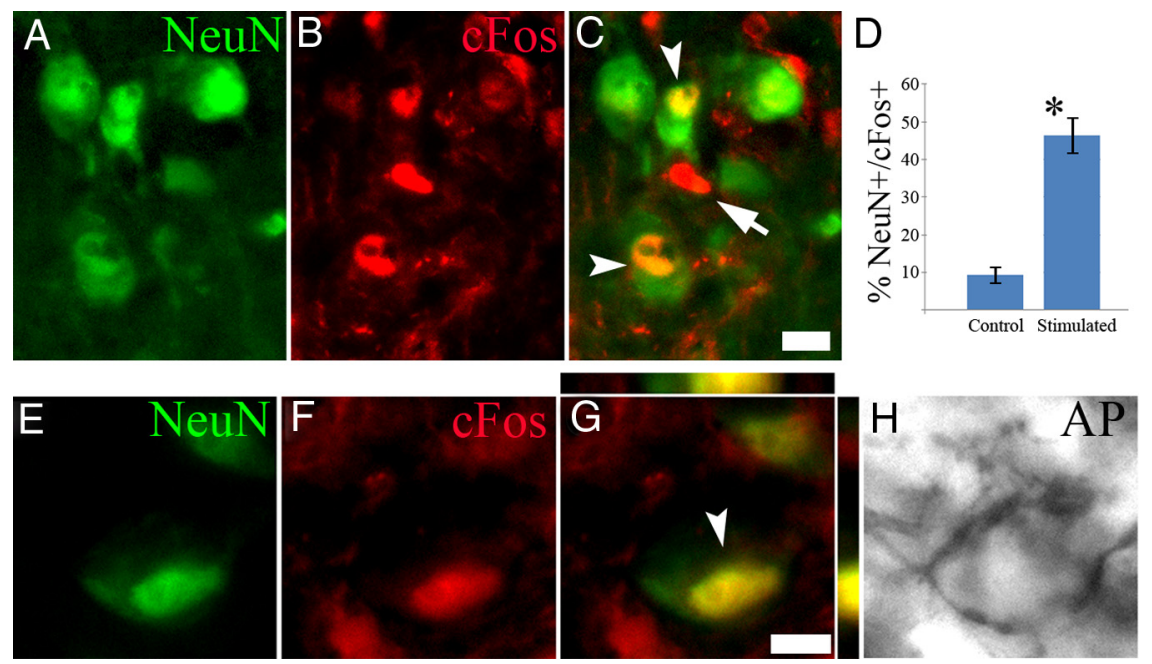

Figure 10. Many graft neurons, but few host DCN neurons, express c-Fos after sciatic nerve stimulation. We found many $\mathrm{NeuN}^{+}$cells in the graft $(\boldsymbol{A}, \boldsymbol{C})$ also expressed c-Fos $(\boldsymbol{B}, \boldsymbol{C})$ after sciatic nerve stimulation. Quantification of NeuN/c-Fos double labeling $(\boldsymbol{A}-\boldsymbol{C})$ demonstrated that $48.5 \%$ of graft neurons $(\boldsymbol{D})$ also expressed c-Fos (arrowheads) compared with just $9.3 \%$ in unstimulated controls. NeuN ${ }^{-} / \mathrm{C}-\mathrm{Fos}^{+}$cells were also present in the graft (arrow, C), indicating that glial cells may also demonstrate an evoked response to sciatic nerve stimulation. A limited number of NeuN ${ }^{+}$neurons $(\boldsymbol{E}, \boldsymbol{G})$ in the DCN expressed c-Fos $(\boldsymbol{F}$; arrowhead, $\boldsymbol{G})$ and were observed near $\mathrm{AP}^{+}$fibers $(\boldsymbol{H})$. Scale bars, $10 \mu \mathrm{m}$. Error bars represent the SD. neurons a viable therapeutic approach. Although numerous studies explored the use of glial progenitors (Keirstead et al., 2005; Davies et al., 2006; Bunge, 2008), neuronal precursors received less attention because of challenges of generating neurons, directing their axons toward intended targets within the injured spinal cord and establishing synaptic connectivity. We have now shown for the first time that graftderived neurons, directed by chemotropic cues, are capable of extending axons through the injured spinal cord, forming synaptic connections with sensory axons at the graft site and host neurons in the brainstem and relaying physiological signals across the injury to the DCN. These findings underscore the advantages of using NRP/GRP grafts and set the stage for restoring functional connectivity with neuronal relays in SCI.

\section{Creating a microenvironment}

\section{conducive to neuronal differentiation} and synapse formation

The rationale for transplanting neural stem cells derived from embryonic stem cells or fetal tissue presumes that cells in a developmental state will retain intrinsic growth properties capable of mediating neural repair. The mature CNS in general and SCI microenvironment in particular present challenges not only for the lack of developmental cues but also the presence of inhibitory cues that promote apoptosis, axon retraction, and scar formation (Nandoe Tewarie et al., 2009). However, permissive astrocytes can modify the injury environment (Smith et al., 1986) and promote formation and maintenance of synapses (Schousboe, 2003). Indeed, our earlier work demonstrated that transplantation of NRP together with GRP produced neurons in the injured spinal cord by creating a microenvironment that promotes neuronal survival and differentiation (Lepore and Fischer, 2005). We now show NRP/ GRP grafts also support regeneration of sensory axons into the graft and promote formation of functional synapses with NRP-derived neurons. Interestingly, the presence of neurons has been shown to induce supportive features of astrocytes, such as the expression of glutamate transporter GLT-1 (Yang et al., 2009) and Figure 9 , suggesting that mutual interactions between neuronal and glial progenitors affects the properties of both phenotypes. Consistent with this interpretation, GRP alone do not support axonal regeneration (Davies et al., 2008), whereas grafts of fetal spinal cord, with similar progenitor populations to NRP/GRP, have demonstrated 
significant integration (Itoh et al., 1996; White et al., 2010).

Intrinsic properties of neuronal progenitors support growth and connectivity

The principal obstacles to axonal growth, accurate navigation, and formation of synaptic connections after SCI are thought to result from the inhibitory environment and cell-intrinsic properties of mature CNS neurons (Selzer, 2003). Indeed, to achieve regeneration and connectivity of sensory neurons in dorsal column lesions, a combination treatment, including conditioning lesion, stromal cell graft, and neurotrophic gradient (Alto et al., 2009), was used to address both extrinsic and intrinsic mechanisms. In contrast, we have demonstrated previously, in vitro, that NRP-generated neurons extend axons across high concentrations of chondroitin sulfate proteoglycans (See et al., 2010) and, in vivo, that graft-derived axons readily cross the glial scar and grow through the white matter along a BDNF gradient (Bonner et al., 2010). In the current study, we focused on the ability of appropriate guidance cues to direct graft axons to a target and support synapse formation with host neurons. Using immuno-EM analysis, we found $\mathrm{AP}^{+}$presynaptic terminals opposed to host neurons with postsynaptic specializations in both the DCN and SN5, demonstrating a surprisingly robust ability for synapse formation. These connections were typically excitatory connections and expressed vesicular glutamate transporters 1 and 2, markers of glutamatergic synapses. We also show evidence of afferent synaptic connections between excitatory host axons and graft neurons in tracing and immuno-EM experiments, underscoring the advantages of combined NRP/GRP grafts. Importantly, almost half of graft neurons expressed c-Fos after sciatic nerve stimulation, demonstrating that their connectivity with sensory axons was robust and active. In contrast, when regenerating dorsal column axons reach the DCN, they fail to form active connections (Alto et al., 2009).

Neural progenitor grafts relay sensory information to the DCN

We describe the neuronal relay at the structural and functional level. Structurally, we have shown host axon regeneration into the graft, synapse formation between sensory axons and graft neurons, graft axon extension, and synapse formation with host neurons in the DCN. We were able to describe the relay in precise anatomical detail because the AP transgene permitted reliable identification of graft-derived neurons and axons, whereas
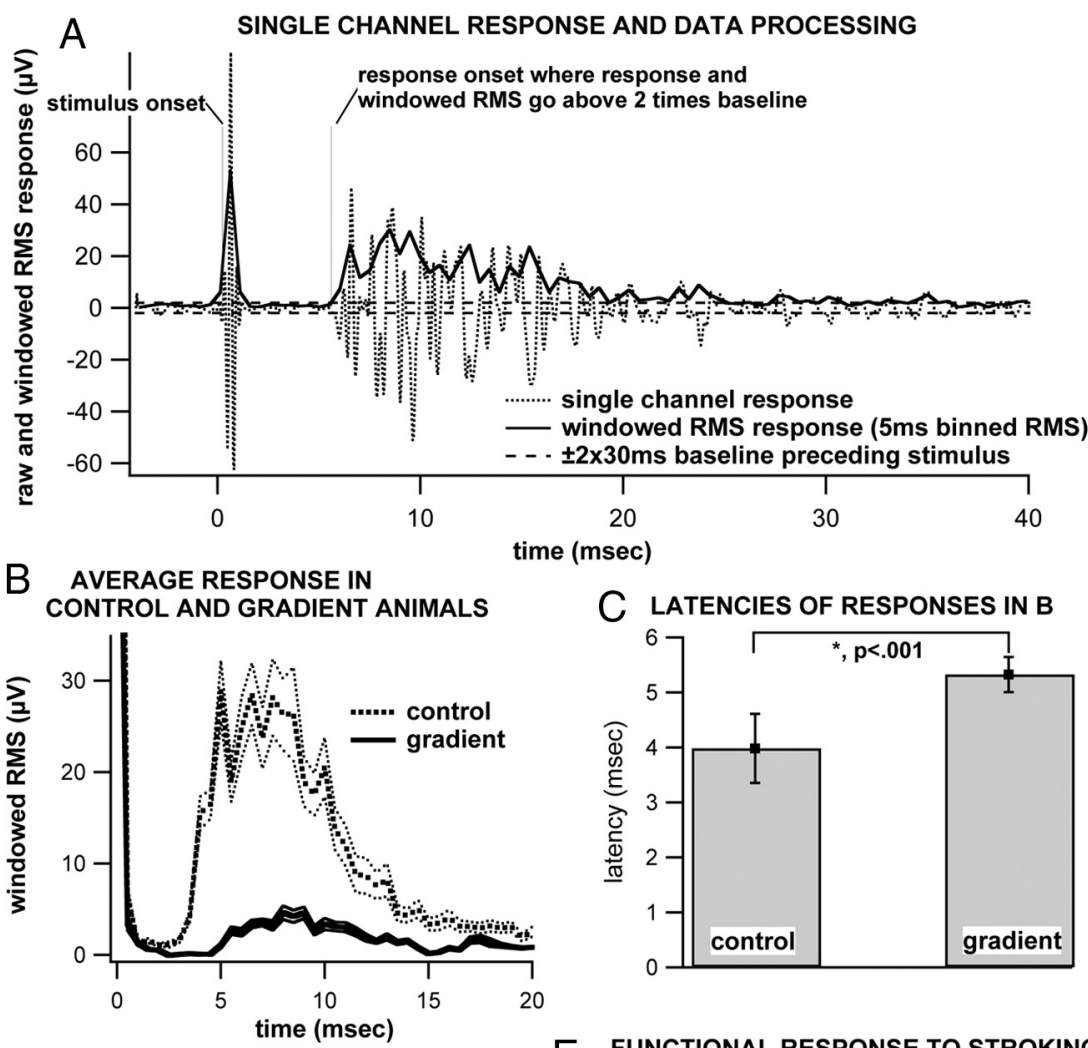

C LATENCiEs Of RESPONSES IN B

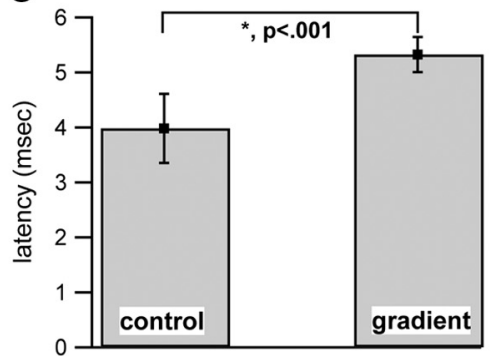

E FUNCTIONAL RESPONSE TO STROKING
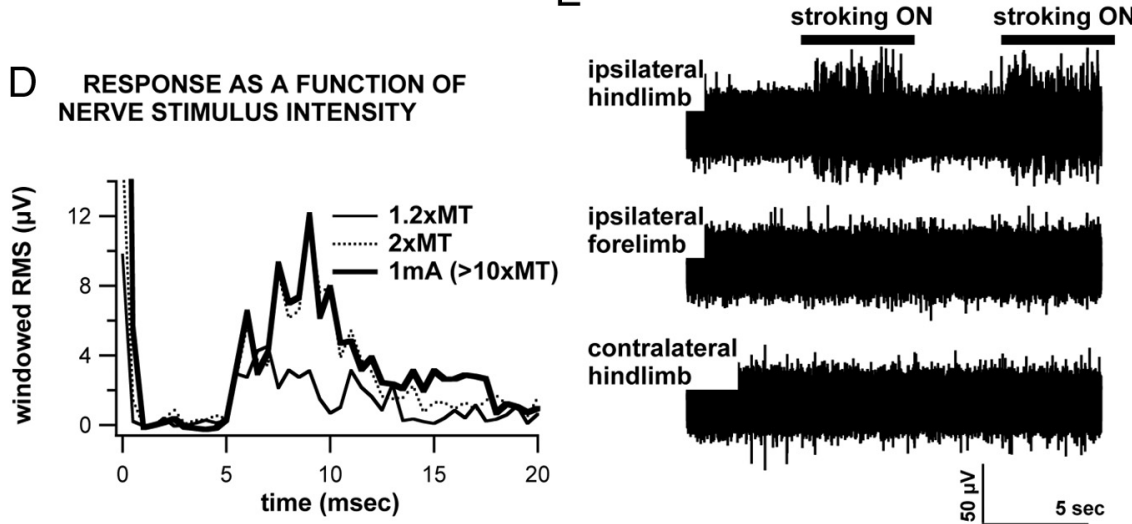

Figure 11. NRP/GRP grafts relay functional signals to the DCN. $\boldsymbol{A}$, The peristimulus average response of a representative channel in a gradient animal. The windowed ( $0.5 \mathrm{~ms}$ window) RMS value of the signal is shown as a heavy-weight line. Dashed lines show twice the background power, calculated using the RMS value of the signal strength in the 4 to 1 ms window before the stimulus. Two vertical lines denote the stimulus time and the onset of the response, defined as the time at which the magnitudes of both the signal and signal windowed RMS become larger than twice the background level. $\boldsymbol{B}$, The average windowed RMS of all channels with $95 \%$ confidence bands in control and gradient animals. Response strength is reduced by a factor of $\sim 5$ in the gradient animals, and the latency increased by $\sim 1.2 \mathrm{~ms}$ compared with the responses in intact animals. $C$, Response latency is significantly increased in gradient animal ( $5.23 \pm 0.32 \mathrm{~ms}$ ) compared with control (3.98 $\pm 0.63 \mathrm{~ms}$ ) (Welch's $t$ test, $p<0.001)$. D, Average response of 16 channels to increasing stimulus intensity in one gradient animal. Shown is the windowed RMS value of the average peristimulus responses of the 16 channels sampled as stimulus strength is increased from $1.2 \times$ motor threshold up to $1 \mathrm{~mA}$. E, Raw single-channel response to paw pinch/stroking of the ipsilateral hindlimb, ipsilateral forelimb, and contralateral hindlimb for one gradient animal. Activity in the dorsal column nuclei increased only for stroking/pinching of the hindlimb ipsilateral to the graft.

Fluoro-Gold and CT $\beta$ unambiguously labeled host sensory neurons. Functionally, we have shown that the evoked responses in the DCN after sciatic nerve stimulation had increased latency (5.2 $\mathrm{ms}$ ), consistent with an additional synapse at the graft and propagation by graft axons but not spared, monosynaptic, host connections (Fig. 11C). When we sampled 32 sites in an injured control (C1 injury only), we found an evoked response at only one site. This response had a latency consistent with intact con- 
trols $(3.9 \mathrm{~ms})$, indicating that it was from a spared fiber. In contrast, responses in the BDNF group were present at all 48 sites sampled and always demonstrated an increase in latency consistent with a relay. To further eliminate the possible contribution of spared fibers, we validated lesion completeness in all graft animals. To eliminate the possible contribution of alternative host pathways to the DCN, we recorded evoked potentials at low stimulation thresholds $(1.2 \times$ and $2 \times \mathrm{MT})$ that only recruit the largest myelinated dorsal column sensory axons and found no change in latency relative to high threshold (1 mA) (Fig. 11D). This finding eliminates the role of small-caliber axons in alternative pathways to the DCN. Finally, we show evoked responses to physiological stimulation (e.g., stroking) of the ipsilateral but not the contralateral hindpaw or ipsilateral forelimb (Fig. $11 E$ ), demonstrating that the response in the DCN was specific to the sensory modality of dorsal columns axons. Although we could not distinguish the contributions of action potential of fibers entering the DCN from postsynaptic cells firing, the limited number of DCN neurons showing c-Fos expression after stimulation of the sciatic nerve suggests that action potentials from graft axons entering the DCN are the major contributor to the responses recorded. We therefore conclude that dorsal column axons made functional synapses with the grafted cells and that graft axons projecting to the DCN are conducting the signals but lack the synaptic strength to depolarize host neurons. This study underscores the ability of embryonic neurons to extend active axons, with proper structural organization that supports conduction of action potentials to the DCN. In contrast, previous reports that regenerating dorsal column axons fail to produce an electrophysiological response (Alto et al., 2009), indicating that these axons may lack proper structural organization.

\section{Strategies to improve relay function}

Analysis of the components of the relay also suggests strategies that could improve functional connectivity by generating postsynaptic responses in target neurons. They include increasing the number of graft neurons (and thereby, their axons), more efficient guidance of graft axons, better conductance, and improved synaptic efficacy through increased spatial or temporal summation. We estimate that our grafts are composed of $10-30 \%$ neurons, a number that could be increased by enriching the graft for NRP or including BDNF with the graft to improve NRP survival. During CNS development, combinations of attractive and repulsive cues guide axons to specific targets. In the current experiment, a single attractive cue, BDNF, guided most graft axons into the DCN, but we did observe axons in other brainstem regions. Thus, a combination of attractive and repulsive cues may improve navigation to the designated target, increasing the number of axons that reach the target as well as the overall fidelity of the relay.

Although action potentials can be transmitted with limited myelination, remyelination enhances conduction and improves function after SCI (Sasaki et al., 2007). Because it is unlikely that graft axons in our study were extensively myelinated, myelination of graft axons would improve function of the relay by allowing the fibers to sustain higher firing rate (Krauthamer and Crosheck, 2002), thereby improving the temporal summation of signals to the DCN. In this respect, the combination of NRP/GRP presents a promising and possibly essential graft composition for any cellreplacement-based repair strategy. Generating actively myelinating oligodendrocytes presents a considerable challenge because the SCI microenvironment promotes astrocyte over oligodendrocyte differentiation (Hill et al., 2004). Still, specific differenti- ation protocols can direct GRP to the oligodendrocyte lineage (Rao et al., 1998), and neurotrophic factors can promote myelination (Cao et al., 2010). Finally, denervation can alter the accessibility, density, and morphology of postsynaptic sites (Kim et al., 2008; Massey et al., 2008), and therefore, activity-dependent training or drug treatments may be required to increase synaptic plasticity of target neurons.

In conclusion, we have developed a transplantation strategy using a mixed population of neuronal and glial progenitors that exploits their intrinsic developmental properties to form a functional relay, as progress toward neuronal replacement therapy. Although this strategy requires additional optimization to achieve behavioral recovery, it demonstrates the therapeutic value of neural stem cells for repair of sensory and possibly motor systems.

\section{References}

Alto LT, Havton LA, Conner JM, Hollis Ii ER, Blesch A, Tuszynski MH (2009) Chemotropic guidance facilitates axonal regeneration and synapse formation after spinal cord injury. Nat Neurosci 12:1106-1113.

Bareyre FM, Kerschensteiner M, Raineteau O, Mettenleiter TC, Weinmann O, Schwab ME (2004) The injured spinal cord spontaneously forms a new intraspinal circuit in adult rats. Nat Neurosci 7:269-277.

Blesch A (2004) Lentiviral and MLV based retroviral vectors for ex vivo and in vivo gene transfer. Methods 33:164-172.

Bonner JF, Blesch A, Neuhuber B, Fischer I (2010) Promoting directional axon growth from neural progenitors grafted into the injured spinal cord. J Neurosci Res 88:1182-1192.

Bunge MB (2008) Novel combination strategies to repair the injured mammalian spinal cord. J Spinal Cord Med 31:262-269.

Cafferty WB, McGee AW, Strittmatter SM (2008) Axonal growth therapeutics: regeneration or sprouting or plasticity? Trends Neurosci 31:215-220.

Cao Q, Xu XM, Devries WH, Enzmann GU, Ping P, Tsoulfas P, Wood PM, Bunge MB, Whittemore SR (2005) Functional recovery in traumatic spinal cord injury after transplantation of multineurotrophin-expressing glial-restricted precursor cells. J Neurosci 25:6947-6957.

Cao Q, He Q, Wang Y, Cheng X, Howard RM, Zhang Y, DeVries WH, Shields CB, Magnuson DS, Xu XM, Kim DH, Whittemore SR (2010) Transplantation of ciliary neurotrophic factor-expressing adult oligodendrocyte precursor cells promotes remyelination and functional recovery after spinal cord injury. J Neurosci 30:2989-3001.

Causing CG, Gloster A, Aloyz R, Bamji SX, Chang E, Fawcett J, Kuchel G, Miller FD (1997) Synaptic innervation density is regulated by neuronderived BDNF. Neuron 18:257-267.

Chen Q, Smith GM, Shine HD (2008) Immune activation is required for NT-3-induced axonal plasticity in chronic spinal cord injury. Exp Neurol 209:497-509.

Cohen S, Greenberg ME (2008) Communication between the synapse and the nucleus in neuronal development, plasticity, and disease. Annu Rev Cell Dev Biol 24:183-209.

Courtine G, Song B, Roy RR, Zhong H, Herrmann JE, Ao Y, Qi J, Edgerton VR, Sofroniew MV (2008) Recovery of supraspinal control of stepping via indirect propriospinal relay connections after spinal cord injury. Nat Med 14:69-74.

Cummings BJ, Uchida N, Tamaki SJ, Salazar DL, Hooshmand M, Summers R, Gage FH, Anderson AJ (2005) Human neural stem cells differentiate and promote locomotor recovery in spinal cord-injured mice. Proc Natl Acad Sci U S A 102:14069-14074.

Davies JE, Huang C, Proschel C, Noble M, Mayer-Proschel M, Davies SJ (2006) Astrocytes derived from glial-restricted precursors promote spinal cord repair. J Biol 5:7

Davies JE, Pröschel C, Zhang N, Noble M, Mayer-Pröschel M, Davies SJ (2008) Transplanted astrocytes derived from BMP- or CNTF-treated glial-restricted precursors have opposite effects on recovery and allodynia after spinal cord injury. J Biol 7:24.

Eftekharpour E, Karimi-Abdolrezaee S, Fehlings MG (2008) Current status of experimental cell replacement approaches to spinal cord injury. Neurosurg Focus 24:E19.

Fischer I, Lepore A, Han S, Tessler A (2006) Cellular replacement in spinal cord injury. In: Textbook of neural rehabilitation and repair (Selzer M, 
Clarke S, Cohen L, Duncan P, Gage F, eds), pp 445-467. New York: Cambridge UP.

Hill CE, Proschel C, Noble M, Mayer-Proschel M, Gensel JC, Beattie MS, Bresnahan JC (2004) Acute transplantation of glial-restricted precursor cells into spinal cord contusion injuries: survival, differentiation, and effects on lesion environment and axonal regeneration. Exp Neurol 190:289-310.

Hunt SP, Pini A, Evan G (1987) Induction of c-fos-like protein in spinal cord neurons following sensory stimulation. Nature 328:632-634.

Itoh Y, Waldeck RF, Tessler A, Pinter MJ (1996) Regenerated dorsal root fibers form functional synapses in embryonic spinal cord transplants. J Neurophysiol 76:1236-1245.

Keirstead HS, Nistor G, Bernal G, Totoiu M, Cloutier F, Sharp K, Steward O (2005) Human embryonic stem cell-derived oligodendrocyte progenitor cell transplants remyelinate and restore locomotion after spinal cord injury. J Neurosci 25:4694-4705.

Kim BG, Dai HN, McAtee M, Bregman BS (2008) Modulation of dendritic spine remodeling in the motor cortex following spinal cord injury: effects of environmental enrichment and combinatorial treatment with transplants and neurotrophin-3. J Comp Neurol 508:473-486.

Krauthamer V, Crosheck T (2002) Effects of high-rate electrical stimulation upon firing in modelled and real neurons. Med Biol Eng Comput 40:360-366.

Kwon BK, Liu J, Lam C, Plunet W, Oschipok LW, Hauswirth W, Di Polo A, Blesch A, Tetzlaff W (2007) Brain-derived neurotrophic factor gene transfer with adeno-associated viral and lentiviral vectors prevents rubrospinal neuronal atrophy and stimulates regeneration-associated gene expression after acute cervical spinal cord injury. Spine 32:1164-1173.

Lepore AC, Fischer I (2005) Lineage-restricted neural precursors survive, migrate, and differentiate following transplantation into the injured adult spinal cord. Exp Neurol 194:230-242.

Mai J, Fok L, Gao H, Zhang X, Poo MM (2009) Axon initiation and growth cone turning on bound protein gradients. J Neurosci 29:7450-7458.

Massey JM, Hubscher CH, Wagoner MR, Decker JA, Amps J, Silver J, Onifer SM (2006) Chondroitinase ABC digestion of the perineuronal net promotes functional collateral sprouting in the cuneate nucleus after cervical spinal cord injury. J Neurosci 26:4406-4414.

Massey JM, Amps J, Viapiano MS, Matthews RT, Wagoner MR, Whitaker CM, Alilain W, Yonkof AL, Khalyfa A, Cooper NG, Silver J, Onifer SM (2008) Increased chondroitin sulfate proteoglycan expression in denervated brainstem targets following spinal cord injury creates a barrier to axonal regeneration overcome by chondroitinase $\mathrm{ABC}$ and neurotrophin-3. Exp Neurol 209:426-445.

McComas AJ (1963) Responses of the rat dorsal column system to mechanical stimulation of the hind paw. J Physiol 166:435-448.

Mujtaba T, Piper DR, Kalyani A, Groves AK, Lucero MT, Rao MS (1999)
Lineage-restricted neural precursors can be isolated from both the mouse neural tube and cultured ES cells. Dev Biol 214:113-127.

Nandoe Tewarie RS, Hurtado A, Bartels RH, Grotenhuis A, Oudega M (2009) Stem cell-based therapies for spinal cord injury. J Spinal Cord Med 32:105-114.

Peters A, Palay SL, Webster HF (1970) The fine structure of the nervous system, Ed 1. New York: Harper and Row.

Rao MS, Noble M, Mayer-Pröschel M (1998) A tripotential glial precursor cell is present in the developing spinal cord. Proc Natl Acad Sci U S A 95:3996-4001.

Sasaki M, Li B, Lankford KL, Radtke C, Kocsis JD (2007) Remyelination of the injured spinal cord. Prog Brain Res 161:419-433.

Sasaki M, Radtke C, Tan AM, Zhao P, Hamada H, Houkin K, Honmou O, Kocsis JD (2009) BDNF-hypersecreting human mesenchymal stem cells promote functional recovery, axonal sprouting, and protection of corticospinal neurons after spinal cord injury. J Neurosci 29:14932-14941.

Schousboe A (2003) Role of astrocytes in the maintenance and modulation of glutamatergic and GABAergic neurotransmission. Neurochem Res 28:347-352.

See J, Bonner J, Neuhuber B, Fischer I (2010) Neurite outgrowth of neural progenitors in presence of inhibitory proteoglycans. J Neurotrauma 27:951-957.

Selzer ME (2003) Promotion of axonal regeneration in the injured CNS. Lancet Neurol 2:157-166.

Smith GM, Miller RH, Silver J (1986) Changing role of forebrain astrocytes during development, regenerative failure, and induced regeneration upon transplantation. J Comp Neurol 251:23-43.

Tom VJ, Houlé JD (2008) Intraspinal microinjection of chondroitinase $\mathrm{ABC}$ following injury promotes axonal regeneration out of a peripheral nerve graft bridge. Exp Neurol 211:315-319.

Verma P, Garcia-Alias G, Fawcett JW (2008) Spinal cord repair: bridging the divide. Neurorehabil Neural Repair 22:429-437.

Wayner MJ Jr, Emmers R (1958) Spinal synaptic delay in young and aged rats. Am J Physiol 194:403-405.

White TE, Lane MA, Sandhu MS, O'Steen BE, Fuller DD, Reier PJ (2010) Neuronal progenitor transplantation and respiratory outcomes following upper cervical spinal cord injury in adult rats. Exp Neurol 225:231-236.

Yang Y, Gozen O, Watkins A, Lorenzini I, Lepore A, Gao Y, Vidensky S, Brennan J, Poulsen D, Won Park J, Li Jeon N, Robinson MB, Rothstein JD (2009) Presynaptic regulation of astroglial excitatory neurotransmitter transporter GLT1. Neuron 61:880-894.

Yao J, Sasaki Y, Wen Z, Bassell GJ, Zheng JQ (2006) An essential role for beta-actin mRNA localization and translation in $\mathrm{Ca}^{2+}$-dependent growth cone guidance. Nat Neurosci 9:1265-1273.

Ziemba KS, Chaudhry N, Rabchevsky AG, Jin Y, Smith GM (2008) Targeting axon growth from neuronal transplants along preformed guidance pathways in the adult CNS. J Neurosci 28:340-348. 